\title{
Compulsivity in anorexia nervosa: a transdiagnostic concept
}

\section{Lauren R. Godier* and Rebecca J. Park}

Oxford Brain-Body Research into Eating Disorders, Department of Psychiatry, University of Oxford, Oxford, UK

\section{Edited by:}

Tanya Zilberter, Infotonic Conseil,

France

\section{Reviewed by:}

Unna N. Danner, Altrecht Eating Disorders Rintveld, Netherlands Carrie J. McAdams, University of Texas at Southwestern Medical School, USA

\section{${ }^{*}$ Correspondence:}

Lauren R. Godier, Oxford Brain-Body Research into Eating Disorders, Department of Psychiatry, University of Oxford, Warneford Hospital, Warneford Lane, Oxford OX3 7JX, UK e-mail: lauren.godier@psych.ox.ac.uk

The compulsive nature of weight loss behaviors central to anorexia nervosa (AN), such as relentless self-starvation and over-exercise, has led to the suggestion of parallels between AN and other compulsive disorders such as obsessive-compulsive disorder (OCD) and addictions. There is a huge unmet need for effective treatments in AN, which has high rates of morbidity and the highest mortality rate of any psychiatric disorder, yet a grave paucity of effective treatments. Viewing compulsivity as a transdiagnostic concept, seen in various manifestations across disorders, may help delineate the mechanisms responsible for the persistence of $\mathrm{AN}$, and aid treatment development. We explore models of compulsivity that suggest dysfunction in cortico-striatal circuitry underpins compulsive behavior, and consider evidence of aberrancies in this circuitry across disorders. Excessive habit formation is considered as a mechanism by which initially rewarding weight loss behavior in AN may become compulsive over time, and the complex balance between positive and negative reinforcement in this process is considered. The physiological effects of starvation in promoting compulsivity, positive reinforcement, and habit formation are also discussed. Further research in AN may benefit from a focus on processes potentially underlying the development of compulsivity, such as aberrant reward processing and habit formation. We discuss the implications of a transdiagnostic perspective on compulsivity, and how it may contribute to the development of novel treatments for AN.

Keywords: anorexia nervosa, compulsivity, obsessive-compulsive disorder, addiction, neurobiology, habit formation, reward

Anorexia nervosa (AN) is a severely debilitating psychiatric disorder characterized by relentless self-starvation with dramatic physiological and psychological effects. It is associated with low rates of recovery (Berkman et al., 2007), and has the highest mortality rate of any psychiatric disorder (Arcelus et al., 2011). Individuals with AN place extreme over-importance on the control of weight and shape, which becomes central to their self-evaluation, and often have disturbed body image perception (Fairburn et al., 2003). These distorted beliefs and perceptions are accompanied by a lack of concern over extreme emaciation, a perpetual drive for thinness and continuous lowering of weight goals (BarbarichMarsteller et al., 2011; see Figure 1 for DSM-V diagnostic criteria). Characteristic behaviors seen in AN to achieve these goals, such as extreme dietary restriction and driven over-exercise, have been described as evidence of compulsivity and aberrant reward processing (Park et al., 2011, 2012; Cowdrey et al., 2013; Kaye et al., 2013a). Indeed the stereotyped and often ritualistic behaviors seen in AN have been compared to that of obsessive-compulsive disorder (OCD; Steinglass and Walsh, 2006), with the two disorders often being reported as comorbid (Halmi et al., 1991), leading to the suggestion that they may share common underlying neurobiological mechanisms (Steinglass and Walsh, 2006). Simultaneously, parallels with addictive disorders such as substance dependence have been increasingly suggested (Zink and Weinberger, 2010; Barbarich-Marsteller et al., 2011; Kaye et al., 2013a), with similarities in the inability to cease behaviors despite adverse consequences.
The aim of this review is to explore how a transdiagnostic view of compulsivity, as a dimension on which several psychiatric disorders may fall, can further our understanding of persistent weight loss behavior in AN. Neurobiological and behavioral correlates of compulsivity will be discussed, with particular focus on how these relate to AN, and parallels with OCD and substance dependence. Better understanding of neurobiological and behavioral processes underpinning compulsive weight loss behavior may aid development of much needed novel treatment strategies for AN.

\section{COMPULSIVE BEHAVIOR IN AN}

Compulsivity can be defined as a trait leading to behavior that is inappropriate to the situation, persists despite having no relationship with any overall goal, and results in undesirable consequences (Dalley et al., 2011). In individuals with AN, dietary restriction tends to take on a driven and compulsive quality. This behavior may be motivated by an aberrant sense of reward, specifically the perceived reward of extreme dietary control and thinness (Fladung et al., 2010, 2013; Park et al., 2011, 2012). In some individuals, such extreme control of eating and weight cannot be sustained, and AN may then be complicated by the development of binge eating and compensatory purging such as self-induced vomiting and/or laxative abuse (Fairburn et al., 2003), which also appears to have an element of compulsivity. Compulsive over-exercising is also a common feature, and is reported to be more prevalent in restrictive $\mathrm{AN}(80 \%)$, compared to the binge/purging subtype 


\section{To be diagnosed as having AN a person must display:}

- Persistent restriction of energy intake leading to significantly low body weight (in context of what is minimally expected for age, sex, developmental trajectory, and physical health)-.

- Either an intense fear of gaining weight or of becoming fat, or persistent behaviour that interferes with weight gain (even though significantly low weight).

- Disturbance in the way one's body weight or shape is experienced, undue influence of body shape and weight on self-evaluation, or persistent lack of recognition of the seriousness of the current low body weight.

\section{Subtypes:}

Restricting Type - During the last three months, the person has not engaged in recurrent episodes of binge eating or purging behaviour (i.e., self induced vomiting or the misuse of laxatives, diuretics, or enemas).

Binge/Purge Type - During the last three months, the person has engaged in recurrent episodes of binge eating or purging behaviour (i.e., self induced vomiting or the misuse of laxatives, diuretics, or enemas).

FIGURE 1 |The DSM-V diagnostic criteria for anorexia nervosa (American Psychiatric Association, 2013).

(43\%; Dalle Grave et al., 2008). The presence of compulsive exercise in AN is extremely challenging to manage and can contribute to medically dangerous degrees of weight loss.

The compulsive behaviors seen in AN have often been compared to those of OCD, but with the obsessional focus being on eating, weight and shape. The compulsions that characterize OCD are defined as repetitive, purposeful actions, which are often performed to reduce the anxiety caused by persistent, intrusive thoughts (Steinglass and Walsh, 2006). In the same way, individuals with AN have persistent, intrusive thoughts regarding food and weight gain, and may develop compulsive, ritualized behaviors in an attempt to neutralize the anxiety associated with these thoughts (Steinglass and Walsh, 2006).

Comorbidity is found to be high between AN and OCD (Halmi et al., 1991) OCD is reported to be most prevalent in the restrictive subtype of AN (Fornari et al., 1992; Lilenfeld et al., 1998), although reported prevalence has been inconsistent across studies (Godart et al., 2002). The presence of obsessive-compulsive symptoms is a risk factor for developing AN (Anderluh et al., 2008); and the level of such symptoms remains elevated to some extent even after recovery (Holtkamp et al., 2005). Familiality is reported, with the first degree relatives of individuals with AN showing an elevated risk for OCD (Bellodi et al., 2001). Candidate gene studies suggest common genetic liability between the two disorders (Mas et al., 2013). Comorbidity with obsessive-compulsive personality disorder (OCPD) is also high (Lilenfeld et al., 2006), and the excessive self-control (Pinto et al., 2014), perfectionism and rigidity seen in OCPD (Ansell et al., 2010) may parallel AN more closely.

Aspects of the compulsive behaviors characteristic of AN have increasingly been compared to the compulsive drug-seeking behavior seen in substance dependence (Scheurink et al., 2010; Zink and Weinberger, 2010; Barbarich-Marsteller et al., 2011; Kaye et al., 2013a). The developmental period of onset is similar, with an initial phase of reward seeking, in the form of weight loss in
AN, which is experienced as rewarding and pleasurable (Scheurink et al., 2010; Park et al., 2011, 2012), as if it were a drug. This is followed by a narrowing of the behavioral repertoire and the lack of ability to cease behaviors despite their adverse consequences (Kalivas and Volkow, 2005). The compulsive drug-seeking behavior of addicts may parallel the relentlessness with which individuals with AN pursue weight loss. Individuals find it increasingly difficult to refrain from weight loss behavior such as restriction and compulsive exercise despite adverse consequences, and even describe symptoms of withdrawal similar to those experienced in drug addiction (Allegre et al., 2006). In terms of comorbidity, there is a higher incidence of substance dependence in ED than the general population: for example, the US National Centre on Addiction and Substance Abuse found that up to 50\% of individuals with an eating disorder abuse substances compared with $9 \%$ of the general population, and up to $35 \%$ of individuals with substance abuse have an eating disorder compared with $3 \%$ of the general population (Casa, 2003; Baker et al., 2013). However, a lower incidence of substance use has been reported in restrictive AN than in other types of eating disorders such as bulimia nervosa (BN) (Holderness et al., 1994; Kaye et al., 2013a). This suggests that there may be a specific relationship between the binge-purge cycle of behavior, which may itself take on an addictive quality, and higher rates of substance abuse (O'Brien and Vincent, 2003).

Nevertheless, there are notable distinctions in information processing between AN, OCD, and substance dependence. In AN, an increased focus on delayed gratification and long term goals is seen (Kaye et al., 2013a). This is reflected in marked differences in the ability to delay reward in AN as compared to substance dependence. Substance dependent individuals and those with binge eating disorder show a preference for smaller immediate reward (Davis et al., 2010), whereas individuals with AN favor delayed larger reward (Steinglass et al., 2012b). That said, starvation in those vulnerable to AN may produce an immediately rewarding 
sense of control (Park et al., 2012), acting as a positive reinforcer of behavior. Equally, avoiding negative consequences such as dysphoric mood during refeeding, which some individuals with AN experience as "withdrawal symptoms" from starvation, may be important short term goals. Perhaps as a consequence of these immediate reinforcers, the long term goal of weight loss becomes irrationally overvalued (Barbarich-Marsteller et al., 2011). Interestingly, individuals with OCPD are more able to delay reward than those with OCD, and this ability to delay reward is associated with perfectionism and rigidity (Pinto et al., 2014). This supports the suggestion that AN may parallel OPCD more closely than OCD. That said, studies looking at decision making processes in AN, OCD, and substance dependence suggest in all three disorders a tendency to make disadvantageous decisions when choosing between immediate or long terms gains (Lawrence et al., 2006; Tchanturia et al., 2007b; Verdejo-Garcia et al., 2007). This impairment in decision making is suggested to be linked to the compulsive and self-destructive behavior seen across these disorders (Tchanturia et al., 2007b). Whilst individuals with AN may show the ability to delay reward in general, their impairment in decision making may lead them to engage in compulsive weight loss behaviors despite adverse outcomes.

\section{COMPULSIVITY AS A TRANSDIAGNOSTIC CONCEPT}

The core feature that unites AN, OCD, and substance dependence is the compulsive nature of disorder-specific behavior. Compulsive weight loss behavior, such as persistent food restriction and over-exercise, is a prominent feature of $\mathrm{AN}$, and is parallel to the compulsive behaviors characteristic of OCD and substance dependence; with inevitable comorbidities. If such parallels reflect similarities in the underlying mechanisms that drive this behavior, there should be some agreement about the neurobiological correlates of aberrant behavior across these disorders. Robbins et al. (2012) have suggested a transdiagnostic approach to compulsivity, arguing that it has cross-diagnostic significance, as evidenced by commonalities and comorbidities in behaviors across a range of disorders. They posit that a transdiagnostic approach to compulsivity may aid in the development of novel treatment avenues relating to specific behaviors, rather than focusing on diagnosis. This focus on constructs of behavior, as opposed to symptoms and disorder categories, reflects the recent RDoC (Research Domain Criteria) research strategy adopted by the National Institute of Mental Health (NIMH). This strategy emphasizes the need to break away from the use of symptoms and diagnostic categories for classification. Instead, research should focus on the variables that define certain dimensions of behavior, or constructs, seen transdiagnostically across psychiatric disorders. In line with this, we suggest that focusing on compulsivity as a transdiagnostic concept may help in understanding commonalities in the compulsive behaviors seen not only in AN but also in other disorders, such as OCD and substance dependence, without categorizing them together unnecessarily.

There is a huge unmet need for translational research in AN to develop novel treatments, especially for adults with severe AN. Effective treatments require an optimal understanding of processes underlying AN, so that the correct treatment targets are identified. The use of a transdiagnostic approach to compulsive weight loss behaviors in AN may begin to address this problem. This review will now focus on the neurobiological and behavioral correlates of compulsivity across disorders and how this can guide novel avenues for the development of treatments for AN.

\section{SUMMARY}

- Parallels are seen between the compulsive nature of behavior in AN, OCD, and substance dependence.

- Despite similarities, important distinctions in disorder-specific compulsivity and information processing are seen across disorders.

- A transdiagnostic view of compulsivity, seen in varying manifestations across disorders, may aid the development of treatments targeting compulsive behavior.

\section{WHAT IS THE NEURAL BASIS OF COMPULSIVITY?}

Models of the neurocircuitry involved in compulsive behavior suggest the involvement of a cortico-striatal circuit, consisting of a striatal and prefrontal component (Robbins, 2007; Brewer and Potenza, 2008; Fineberg et al., 2010). The striatal component is seen as responsible for driving compulsive behavior, while the prefrontal component controls or inhibits this behavior. Abnormalities in either of these components (hypoactivity/hyperactivity) may result in an increase in compulsive behavior. The caudate nucleus (the striatal component) is suggested to drive compulsive behaviors, with the orbitofrontal cortex (OFC, the prefrontal component) exerting inhibitory control over these (see Figure 2). This is distinct but related to an "impulsive" cortico-striatal circuit, involving the ventral striatum (VS)/nucleus accumbens (NAc) (striatal component), and the anterior cingulate cortex (ACC)/ventromedial prefrontal cortex (vmPFC; prefrontal component). These compulsive and impulsive circuits are suggested to be intercommunicating, with the possibility that abnormalities in one circuit lead to abnormalities in the other (Fineberg et al., 2010). This is relevant for theories of dependence in which it is suggested that what may begin as impulsive behavior may eventually become compulsive with repetition of behavior, with a corresponding shift in control from impulsive to compulsive neural circuitry (Everitt and Robbins, 2005). This may relate to eating disorders involving binge/purge behaviors, in which the behaviors may initially be driven by impulsivity rather than compulsivity.

This compulsive cortico-striatal circuit can be illustrated using tasks which are thought to measure compulsivity. Failures in reversal learning, the ability to adapt behavior following negative feedback, have been suggested to reflect cognitive inflexibility, meaning a rigid cognitive style, which may contribute to compulsivity (Fineberg et al., 2010). Reversal learning is impaired by lesions to the OFC (Dias et al., 1996; Berlin et al., 2004; Remijnse et al., 2006), an area selectively activated during reversal learning tasks (Hampshire and Owen, 2006). Lesions to the medial striatum have also been shown to produce impairments in reversal learning in monkeys (Clarke et al., 2008), supporting the suggestion that a cortical and striatal component is involved in compulsive behavior. Set-shifting tasks, in which attention is required to switch between multiple tasks, or elements of a task (Miyake et al., 2000), is also thought to measure cognitive inflexibility (Fineberg et al., 2010). Lesions to the lateral PFC in primates (Dias et al., 1996) and the 


\section{Compulsive Neurocircuitry}

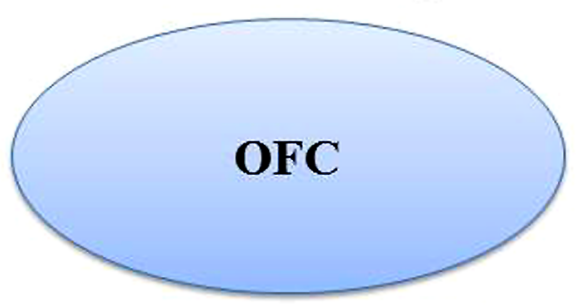

$=$ Prefrontal

component

$=$ Striatal

component
'Top down'

inhibitory control

over compulsive

behaviour

\section{Caudate Nucleus}

FIGURE 2 | Representation of the cortico-striatal circuitry suggested to be involved in the development compulsive behavior (Robbins, 2007; Brewer and Potenza, 2008; Fineberg et al., 2010). In the circuit, activity in the striatal component drives compulsive behavior, whilst activity in the prefrontal component inhibits compulsive behavior. Both failures in "top down" control of the prefrontal components, and over activity of "bottom up" striatal activity can result in increases in compulsive behavior. Abbreviation: OFC, orbitofrontal cortex. ventrolateral PFC in humans (Hampshire and Owen, 2006) impair performance on set-shifting tasks. Failures in both these types of task, and the corresponding neuroanatomy, suggest that impairments in "top down" cortical control may underpin compulsive behavior, and over activity of striatal regions may also underpin, or exacerbate compulsivity.

\section{ARE NEURAL AND BEHAVIORAL CORRELATES OF COMPULSIVITY OBSERVED IN AN, OCD, AND ADDICTION?}

Dysfunction of the neurocircuitry implicated in compulsivity can be seen across AN, OCD, and addiction (see Table 1). In terms of a dysfunctional striatal component, $\mathrm{AN}$ has been associated with increased caudate function, measured both directly during a monetary reward task (Wagner etal., 2007) and indirectly during exposure to aversive food stimuli (Cowdrey etal., 2011). In OCD, increased functional connectivity within the cortico-striatal circuitry has been shown to correlate positively with Y-BOCS score, together with increased volume and activity in the caudate nucleus (Hou et al., 2013). Evidence of increased activity in the caudate nucleus (Saxena etal., 1998) and alterations in caudate volume have also been reported in OCD (Scarone et al., 1992). In contrast to $\mathrm{AN}$ and OCD, chronic substance use has been associated with decreased activation of the caudate during reward anticipation (van Hell et al., 2010). However, high scores on self-reported food addiction have been associated with increased activation in the caudate (Gearhardt et al., 2011), suggesting there may be differences in caudate activation between behavioral and substance addictions.

Decreased activation of a prefrontal component can also be seen across disorders. Reduced activity in the OFC whilst viewing disorder-related stimuli has also been found in AN (Uher et al., 2004), and alterations in OFC volume has been reported (Frank et al., 2013). Reduced activation of the OFC during reversal learning has been found in individuals with OCD and their unaffected relatives (Chamberlain et al., 2008), and abnormalities in OFC gray matter have been found in both OCD (Menzies et al., 2008), and substance dependence (Franklin et al., 2002) Reduced functional connectivity of the right inferior and superior OFC has been related not only to self-reported compulsivity in OCD but also to compulsive drug taking in substance dependence (Meunier et al., 2012).

Abnormalities in the "compulsive" circuit are implied by deficits in neuropsychological tasks thought to tap this construct (see Table 1). Individuals with $\mathrm{AN}$ are often described as having low cognitive flexibility (Tchanturia et al., 2004), and consistently show 


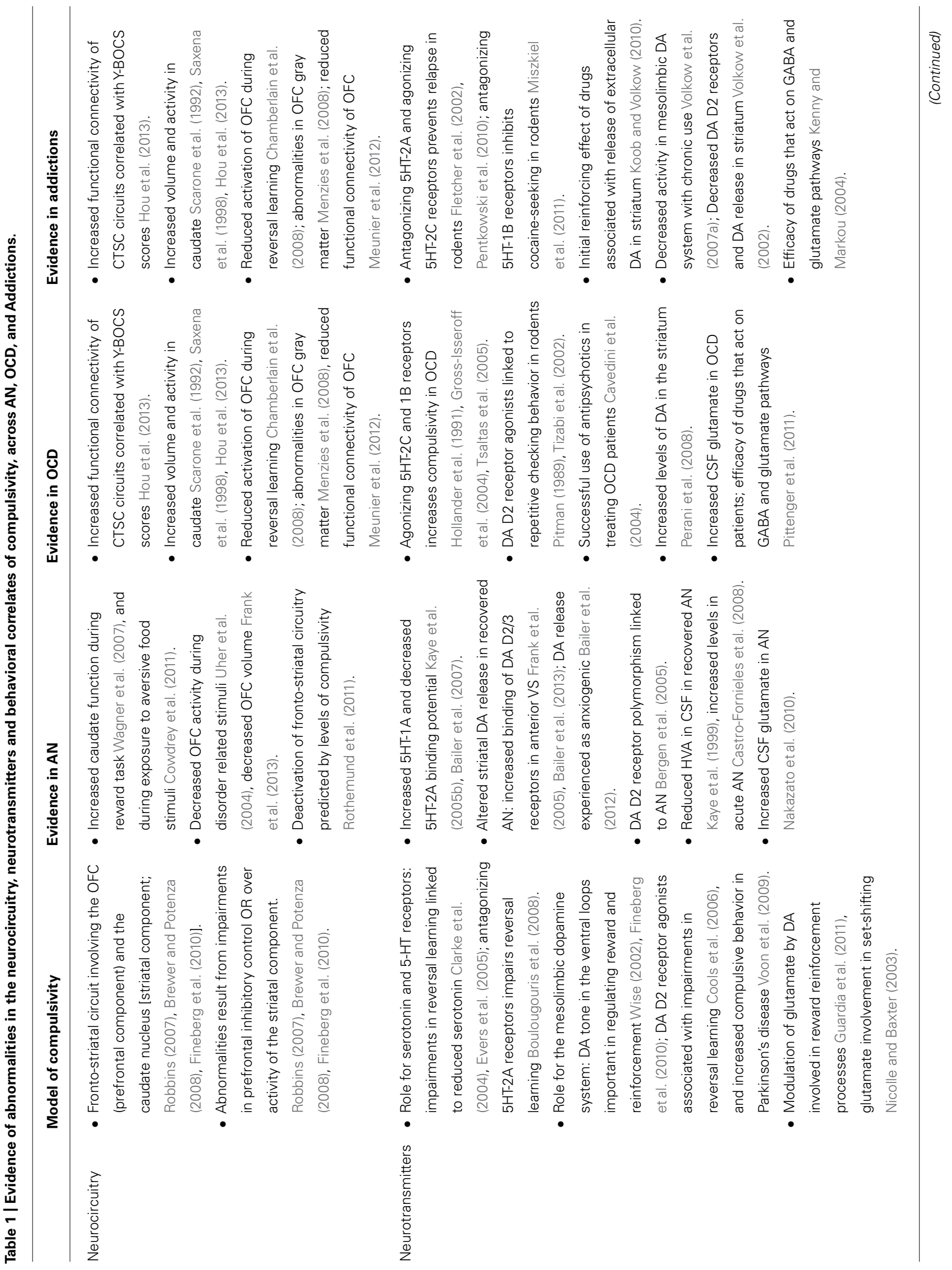




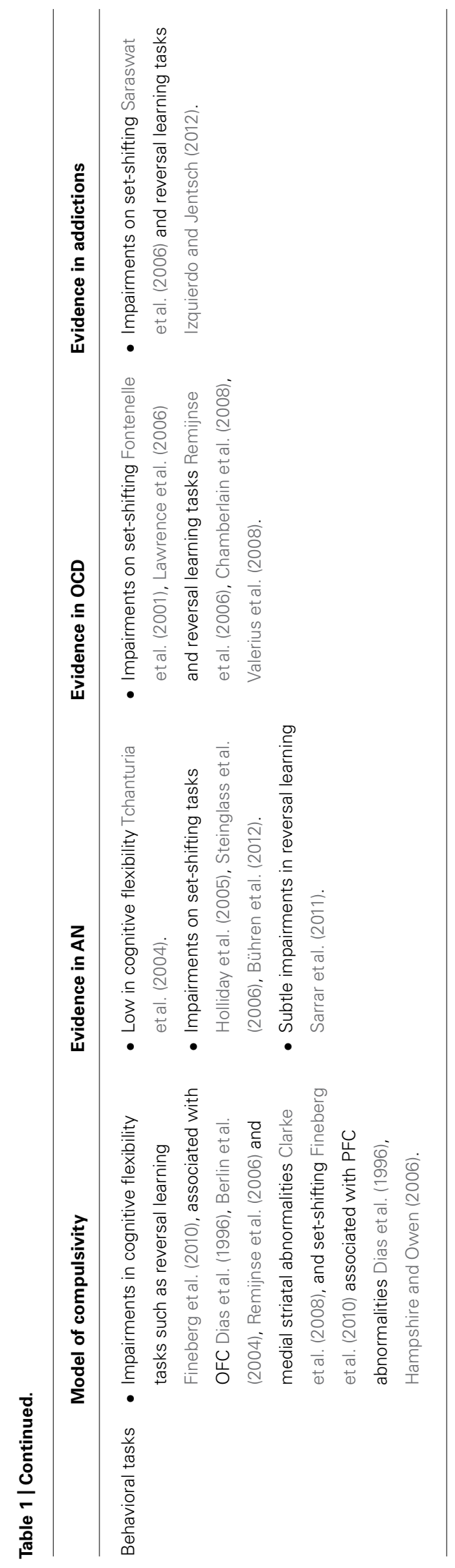


poor set-shifting abilities (Holliday et al., 2005; Steinglass et al., 2006; Bühren et al., 2012). Poor set-shifting has been suggested as an endophenotype of both $\mathrm{AN}$ and $\mathrm{BN}$, and is associated with both longer illness duration and increased disorder-related rituals (Roberts et al., 2010). Subtle impairments in reversal learning have also been reported in $\mathrm{AN}$, and are shown to occur before and after weight gain (Sarrar et al., 2011), suggesting this is a trait rather than state related impairment. OCD and substance dependence have also both been associated with deficits in reversal learning (Remijnse et al., 2006; Chamberlain et al., 2008; Valerius et al., 2008; Izquierdo and Jentsch, 2012), and set-shifting (Fontenelle et al., 2001; Lawrence et al., 2006; Saraswat et al., 2006).

\section{NEUROTRANSMITTER INVOLVEMENT IN COMPULSIVITY The role of serotonin}

Serotonin has widespread effects on satiety, impulse control and mood, with a range of evidence indicating a specific role for 5-HT receptors in compulsive behavior (see Table $\mathbf{1}$ ). A rodent model of OCD indicates that 5-HT-2C receptor agonists increase compulsivity or the persistence of response in these rats (Tsaltas et al., 2005). This result has been replicated in exacerbating compulsive symptoms in human OCD patients (Hollander et al., 1991), in whom 5-HT-1B receptor agonists also exacerbate OCD symptoms (Gross-Isseroff et al., 2004). Impairments in reversal learning have been linked to reduced brain serotonin (Evers et al., 2005), particularly in areas such as the OFC (Clarke et al., 2004), and antagonism of 5-HT-2A receptors impairs reversal learning (Boulougouris et al., 2008), indicating their involvement in the development of compulsive behavior.

The 5-HT system has been extensively studied in AN, with much evidence of dysfunction in this system (for a recent review see Kaye et al., 2013b). Imaging studies have consistently shown increased 5HT-1A and decreased 2A receptor binding potential in individuals both currently ill and recovered from AN (Kaye et al., 2005a,b; Bailer et al., 2007), suggesting a trait and not state related alteration. Interaction between $5 \mathrm{HT}-1 \mathrm{~A}$ and $2 \mathrm{~A}$ receptors in the medial prefrontal cortex ( $\mathrm{mPFC}$ ) have been suggested to modulate impulsivity and compulsivity (Carli et al., 2006), although there is yet to be evidence of this mechanism in the development of compulsive behavior in AN.

The 5-HT system is modulated by many drugs of abuse (Kirby et al., 2011). Research in this area is extensive, the scope of which cannot be covered in this review. However, evidence to date points to a particular role for $5 \mathrm{HT}-2 \mathrm{~A}$ and $2 \mathrm{C}$ receptors in relapse during withdrawal, and in the persistence of compulsive drug-seeking in addiction (Fletcher et al., 2002; Pentkowski et al., 2010). Furthermore, there is an inhibitory effect of 5-HT-1B receptor antagonists on cocaine-seeking behavior (Miszkiel et al., 2011). In terms of behavioral addictions, peripheral measures suggest reduced serotonin levels in pathological gamblers (Nordin and Sjödin, 2006). This has been hypothesized to be linked to maladaptive decision making in these individuals (Kirby et al., 2011), and treatment with SSRIs has been reportedly effective (Hollander and Rosen, 2000). Although aberrancies in the 5-HT system are seen across compulsive disorders, these do not appear to be universal in nature, suggesting that the serotonergic neurotransmitter system alone is not driving compulsive behavior.

\section{The role of dopamine}

Dopamine (DA) is considered key to the rewarding effects of both natural and drug-derived reward (Volkow et al., 2012b), and the mesolimbic DA pathways in particular play a crucial role in reward and reinforcement processes (Wise, 2002). Models of compulsivity have emphasized the importance of DA tone in the ventral loops that link the ventral ACC and the VS/NAc in regulating reward and reinforcement behaviors (Fineberg et al., 2010; see Table 1). DA D2 receptor agonists such as levodopa have been associated with deficiencies in reversal learning (Cools et al., 2006), and increased compulsive behavior in Parkinson's disease (Voon et al., 2009). Studies in animals have also shown that the administration of DA agonists induces stereotyped behaviors associated with OCD (Pitman, 1989). Specifically, the use of a selective D2 receptor agonist in rats was associated with the development of repetitive checking behavior (Tizabi et al., 2002). DA dysfunction in OCD patients is also indicated by the successful use of antipsychotics when SSRI treatment is unsuccessful (Cavedini etal., 2004). There have also been reports of increased levels of DA in the striatum in OCD (Perani etal., 2008).

A key process in the initial reinforcing effect of drugs is their ability to produce increases in extracellular DA in limbic regions such as the NAc/VS (Koob and Volkow, 2010). This release of DA is associated with a feeling of euphoria, and is experienced as rewarding (Volkow et al., 1996), thus positively reinforcing their use. The expectation of drug reward (i.e., in certain contexts) is also important in reinforcing drug use (Volkow et al., 2003), and is likely to depend on neurotransmitters such as glutamate, which is known to modulate DA release in the NAc (Kalivas and Volkow, 2005). These DA- dependent effects cause drugs themselves and drug-associated stimuli to gain incentive salience and promote further drug-seeking behavior (Everitt and Robbins, 2005). This repeated and prolonged DA increase results in synaptic changes in DA pathways, and these changes may be responsible for the formation of compulsive habits that persist despite adverse consequences in substance dependence (Wolf, 2002).

In substance dependent individuals, activity in the mesolimbic DA system is decreased, a deficiency that persists for months following detoxification (Volkow et al., 2007a). Chronic cocaine abusers are shown to have decreased levels of D2 receptors and a decrease of DA release in the striatum (Volkow et al., 2002), although initial drug use is associated with synaptic increases in DA (Volkow et al., 2007a). Evidence of decreased DA activity following chronic drug use has led to the suggestion that this deficiency in DA may cause an increase in the compulsion to seek further drug reward to order to increase deficient DA levels, with repetition of this behavior leading to a dependence on the substance (Fineberg et al., 2010). In contrast, individuals recovered from AN have increased binding of DA D2/D3 receptors in the anterior VS while currently ill AN patients has shown increased levels of the DA metabolite homovanillic acid (HVA) in cerebrospinal fluid (Castro-Fornieles et al., 2008). The increased DA receptor binding in recovered AN patients contrasts with the reduced striatal DA binding found in those with substance abuse (Volkow et al., 2009, 2012a), which is paralleled by those with BN (Broft 
et al., 2012), and obesity (Kenny, 2011). Striatal DA response has been negatively associated with binge eating and vomiting (Broft et al., 2012), suggesting that individuals who engage in overeating may have reduced DA function, similar to that found in substance dependence. DA release in the dorsal putamen has been associated with anxiety in recovered AN, which contrasts with the euphoria reported by controls (Bailer et al., 2012). Palatable food ingestion is associated with DA release in the striatum (Bassareo and Di Chiara, 1999), suggesting that individuals with AN may experience this DA release as aversive, as opposed to the hedonic response seen in healthy controls. This aversive reaction to food may explain the relentless food restriction seen in AN (Kaye et al., 2013a).

Glutamate is the principal excitatory neurotransmitter in the brain and is involved in many cognitive functions such as memory and learning (Jamain et al., 2002). The mesolimbic DA system, central to brain reward processes and compulsivity, has a variety of excitatory glutaminergic and inhibitory gamma-amino butyric acid (GABA, of which glutamate is the precursor) inputs (Guardia et al., 2011). The NAc, a region heavily implicated in reward processes, has glutaminergic inputs from limbic regions, and GABAergic projections to other reward-related areas (Guardia etal., 2011). There is extensive physiological and neurochemical evidence to suggest that reward-related learning requires an interaction between DA and glutamate, and occurs as the result of modulation by DA of glutamate synapses in the striatum (Beninger and Gerdjikov, 2005). Alterations in glutamate receptor binding in the cingulate cortex and dorsal striatum has been associated with impairments in set-shifting ability (Nicolle and Baxter, 2003), further suggesting a role for glutamate in cognitive flexibility and compulsivity.

Dopamine modulation of glutamate has been implicated in the development and expression of addictive behaviors, and there is evidence suggesting that modulation of GABA and glutamate pathways may be effective in the treatment of substance use disorders (Olive et al., 2012). Animal studies have shown the efficacy of GABA agonists in attenuating the positive reinforcing effects of drugs, and glutamate antagonists may be effective in preventing relapse (Kenny and Markou, 2004). Drugs modulating glutaminergic and GABAergic pathways have also been shown to act on binge eating, purging and weight loss in eating disorders (Guardia et al., 2011). Interestingly, both OCD and AN are associated with an increase in cerebrospinal fluid glutamate (Nakazato et al., 2010; Pittenger et al., 2011). Although successful treatment with glutaminergic drugs has yet to be reported in AN, some improvement has been found in the treatment of OCD (Pittenger et al., 2011).

\section{SUMMARY}

- Models of compulsivity indicate a bottom up striatal component driving compulsivity, and a top down prefrontal component inhibiting compulsive behavior.

- Dysfunction of this neurocircuitry, and impairments in tasks reflecting activity in these regions, can be seen in AN, OCD, and substance dependence.

- Abnormalities in neurotransmitter activity linked to impulse control and reward, such as DA, glutamate and serotonin, are also seen across disorders.

\section{DOES COMPULSIVITY REFLECT DYSREGULATED HABIT FORMATION?}

Compulsivity, as previously defined, can also be described as a tendency to carry out repetitive acts in a habitual manner (Fineberg et al., 2010). Habits are described as behaviors that are not innate, are engaged in repeatedly and become fixed, occur without conscious effort and can be elicited by external stimuli (Graybiel, 2008). Two distinct types of learning are involved in the development of behavior that is not innate or is outside of conscious awareness: action-outcome learning and stimulus-response learning (Robbins et al., 2012). Action-outcome learning (also referred to as goal-directed learning) occurs when a particular action leads to a rewarding outcome. If at any point the action no longer leads to reward, the frequency of that action will decrease (Balleine and O'Doherty, 2010). However, if these new actions are engaged in repeatedly (over-trained), they may become insensitive to the outcome, and will be repeated even when they do not result in reward (stimulus-response learning; Graybiel, 2008). Thus, behavior can become a habitual response to environmental stimuli associated with the rewarding outcome (Steinglass and Walsh, 2006). Despite the suggested distinction between goal-directed and habit learning, early description of habits describe them as a form of automatic goal-directed behavior. Bargh (1989) suggests that habits form as the instrumental link between goals and actions, and are automatically activated when a relevant goal is present. This may be particularly relevant for disorders such as $\mathrm{AN}$, in which automatic habits, which take the form of compulsive weight loss behaviors, may occur unconsciously in the persistent presence of long term weight loss goals.

Research indicates neural distinctions between goal-directed and habit learning. In humans, the ventromedial PFC has been linked to goal directed learning (Daw etal., 2005), while the putamen has been linked to habit learning (Tricomi et al., 2009). Cortico-striatal connectivity as indexed by diffusion tensor imaging (DTI), which measures the strength of white matter tracts has been associated with differences in habit and goal-directed control of actions (de Wit et al., 2012). In a behavioral learning task, the tendency to rely on habits was associated with white matter tract strength between both premotor cortex and posterior putamen, and gray matter density in the posterior putamen; while the tendency to use goal directed control was associated with tract strength in the ventromedial PFC from the caudate (de Wit et al., 2012). The cortico-striatal circuitry implicated in habit vs. goal directed behavioral control is similar to that suggested in models of the neurocircuitry of compulsivity (see Figure 2), supporting the suggestion that compulsive behavior may be underpinned by habitual control of behavior, as these constructs appear to be indexed by overlapping neurocircuitry. Investigating abnormalities in habit learning and related brain areas may thus further understanding of the development of compulsive behavior across disorders.

\section{IS EXCESSIVE HABIT FORMATION OBSERVED IN AN, OCD, AND SUBSTANCE DEPENDENCE?}

Emergent evidence suggests that dysregulation of habit formation may provide a mechanism by which the development of well-entrenched, compulsive behaviors can occur: for example, 
once drug taking is engaged in repeatedly, it becomes associated with a number of environmental stimuli or cues, which thereby become triggers for compulsive drug-seeking and drug taking, despite knowledge of the negative consequences of engaging in this behavior (Belin et al., 2011). Habit learning may also play a role in disorders such as AN and OCD, in which certain compulsive, and sometimes ritualistic, behaviors may persist despite a lack of reward or intermittent reward, and a wide variety of negative consequences (Steinglass and Walsh, 2006).

The development of substance dependence has been described in terms of a transition from initially goal-directed drug taking, driven by the reinforcing properties of the drug, to progressively more compulsive drug-seeking controlled by the habit system (Everitt and Robbins, 2005), and ultimately driven by environmental stimuli associated with the drug (Belin et al., 2011). Animal models of compulsive drug-seeking have investigated habit formation using outcome devaluation paradigms, in which previously rewarding action-outcome contingences are devalued, and persistence of behavior despite this devaluation is measured. These demonstrate that reinforcement with cocaine, in comparison to a natural reward such as lemon-sucrose solution, resulted in accelerated habit learning, and was subsequently less sensitive to devaluation (Miles et al., 2003). Similar results have been found with other drugs of abuse, such as alcohol (Dickinson et al., 2002), suggesting that the reinforcing effects of drugs may promote dominance of the habit system in learning and result in the development of compulsive drug-seeking behaviors. Everitt and Robbins (2005) support this idea with a neural systems model of substance dependence, in which this transition from goal directed to habitual control represents a change from prefrontal cortical to striatal control, and a progression from ventral to dorsal areas of the striatum (Everitt and Robbins, 2005). This is supported by rodent studies (Ito et al., 2000, 2002), and data from human cocaine addicts showing increased dorsal striatum activity during presentation of drug cues (Volkow et al., 2006). Drugs of abuse may also decrease the ability of the individual to exert control over these habits, even when presented with persistent negative and aversive consequences (Deroche-Gamonet et al., 2004). A parallel can be drawn here with the compulsive behaviors seen in AN: individuals with AN often report wanting to recover from their disorder, despite persisting with compulsive behavior that maintains their emaciation.

Compulsive behavior in OCD may also be associated with overreliance on habits in learning; Gillan et al. (2011) showed that individuals with OCD had a selective impairment in goal directed control of behavior which forced them to rely on previously learned habits. Although individuals with OCD showed no overall impairment in using feedback to guide learning, they showed weaker knowledge of the direct causal relationship between actions and outcomes, leading to errors. Symptom severity was predictive of persistent responding to devalued stimuli, suggesting the continued use of previously learned habits may be related to the severity of compulsions (Gillan etal., 2011). Using a shock avoidance paradigm, Gillan et al. (2013) also demonstrated that individuals with OCD have a tendency to develop excessive avoidance habits, further supporting the idea that a reliance on habit formation in learning at the expense of goal directed control may underlie compulsive behaviors in OCD.
Walsh (2013) elegantly outlines the mechanisms by which aberrant habit formation may contribute to the maintenance of AN. It is suggested that restrictive eating may begin as the result of goal-directed weight loss behavior, in which behavior becomes associated with a rewarding outcome (weight loss). If this restrictive eating behavior is repeated enough it may become relatively insensitive to reward. In this way, weight loss behavior becomes highly practiced and over trained, and weight loss as a rewarding outcome may be needed only intermittently, or even no longer necessary for this behavior to continue. The fact that habitual behavior is outcome-independent makes it highly resistant to change, reflecting the treatment resistance often seen in individuals with AN (Walsh, 2013). It is further suggested that during the process of habit formation in $\mathrm{AN}$, restrictive behavior itself becomes rewarding through conditioned reinforcement (Walsh, 2013), in which a set of cues begin to develop, and take on rewarding properties themselves (Everitt and Robbins, 2005). Individuals with AN may thus start to find that the reward of weight loss is no longer required as the now habitual weight loss behaviors themselves and associated cues have become rewarding or reinforcing. This process is also seen in substance dependence, in which cues associated with drug taking become associated with craving for the drugs and drug taking (Wikler, 1973).

Rothemund et al. (2011) reported that high levels of compulsivity in severely low weight AN patients predicted deactivation of the fronto-striatal circuitry, a finding that was interpreted as reflecting the transition from goal-directed actions to the development of habitual compulsive behavior, similar to that described in substance dependence (Everitt and Robbins, 2005). During the high calorie picture conditions in this study, individuals with AN showed increased activation in the right caudate and right precuneus, suggested to reflect differences in automatic habit learning processes compared to control participants. Furthermore, reduced gray matter volume in the bilateral OFC and right middle and superior frontal gyrus was found in individuals with AN, indicative of dysfunctional goal-directed behavioral control. The results of this study suggest aberrancies in the neurocircuitry associated with goal directed actions and habits in AN, which may reflect the persistence of compulsive weight loss behaviors in this disorder.

\section{SUMMARY}

- Excessive reliance on stimulus-response habits in learning may underpin the development of compulsive behaviors, with evidence of this in both OCD and substance dependence.

- Models of addiction suggest a transition over time from initially goal directed to habitual behavior, reflected by a shift in corresponding neurocircuitry.

- Recent theory implicates habit formation in the development of compulsive weight loss behaviors in AN, but to date there is no published evidence testing this theory.

\section{THE ROLE OF POSITIVE AND NEGATIVE REINFORCEMENT IN COMPULSIVITY}

Whilst AN and OCD have often been conceptualized as disorders driven by avoidance and fear of weight gain in $\mathrm{AN}$, and of disorder related obsessions in OCD- substance dependence is commonly 
thought to be driven by an approach response, to gain the rewarding effects of drugs. If compulsive behavior is driven by a common process in these disorders, there should be some similarities in the reinforcement processes maintaining compulsive behavior.

\section{POSITIVE AND NEGATIVE REINFORCEMENT IN AN}

AN has often been associated with anhedonia and a negative mindset, with the suggestion that compulsive self-starvation serves to reduce the anxiety and negative affect that becomes associated with food (Zink and Weinberger, 2010). Indeed, food ingestion may be experienced as anxiogenic for individuals with AN (Bailer et al., 2012). This may provide one mechanism through which individuals with AN experience self-starvation as a relief from this food associated anxiety, and indicates that negative reinforcement plays a big role in the maintenance of AN. Furthermore, compulsive exercise behavior has been associated with high levels of anxiety and depression in $\mathrm{AN}$, and may serve as a means of reducing these negative states (Meyer et al., 2011).

However, the maintenance of restrictive behavior in AN may also involve positive reinforcement processes. Selby et al. (2014) suggest a model in which positive emotions associated with successful weight loss, such as feelings of pride and accomplishment, reinforce and drive further weight loss behavior. Over time, weight loss behavior is conditioned to elicit positive emotions regardless of whether further weight loss is attained (Selby et al., 2014). The underlying premise of this theory is consistent with that of Walsh's habit formation theory (Walsh, 2013). Evidence that weight loss behavior in AN may be driven by positive reinforcement comes from a series of functional magnetic resonance imaging (fMRI) studies. Fladung et al. (2010) found that positive feelings and increased activation in the VS were associated with underweight pictures in individuals with $\mathrm{AN}$, with reduced VS activation during the normal weight pictures. This was in comparison to healthy individuals, who showed the opposite pattern of activation in the VS. In a further study, Fladung et al. (2013) found that this VS signal may change over time, in the same way that neural activation evolves over time in substance dependence. In this second study, individuals with AN, whose illness duration was five times shorter than those in the first study, showed the same increased activation to underweight pictures and decreased activation to normal weight pictures in comparison to healthy controls. However, the signal did not differ between categories, suggesting that the signal in the VS may evolve over time, as the illness duration increases. The authors suggest that over time cues associated with self-starvation are linked to strong motivational value, which further reinforces starvation and weight loss behavior (Fladung et al., 2013). Increased positive feelings and a pronounced attentional bias to stimuli depicting physical activity has also been found in AN (Giel et al., 2013).

\section{A SHIFT FROM POSITIVE TO NEGATIVE REINFORCEMENT?}

Selby et al. (2014) suggest that positive emotion/reinforcement may be particularly relevant in the initial stages of $\mathrm{AN}$, with negative reinforcement becoming more important in maintaining behavior over time, where weight loss behavior is used to reduce negative emotions. It may be that the later stages of AN and drug dependence are similar, in that the early rewarding effects of food restriction and drug-taking may both cause these behaviors to be repeated and become habitual/compulsive in nature (Zink and Weinberger, 2010). This could be reflected by synaptic changes in both substance dependence and AN (Everitt and Robbins, 2005; Fladung et al., 2013).

The synaptic changes seen over time in drug dependence are well studied. The initial DA-dependent reinforcing effect of drugs is associated with a feeling of euphoria, and is experienced as rewarding (Volkow et al., 1996), thus positively reinforcing their use. These DA-dependent effects cause drugs themselves and drugassociated stimuli to gain incentive salience and promote further drug-seeking behavior (Everitt and Robbins, 2005). The repeated and prolonged DA increase results in synaptic changes in DA pathways, and these changes may be responsible for the formation of compulsive habits in substance dependence (Wolf, 2002). These later stages of habitual drug-seeking and taking may be negatively reinforced by the withdrawal symptoms experienced in absence of the drug, during which individuals can experience both physical and emotional negative states (Koob and Volkow, 2010). Protracted withdrawal is associated with hypofunctioning of the DA pathways and anhedonia (Volkow et al., 2007b), which may result in an increased drive for further drug-seeking to counteract this. Avoiding these withdrawal symptoms is likely to play a big role in reinforcing drug use, suggesting that the later stages of compulsive drug use may also involve negative reinforcement.

The complex interplay of positive and negative reinforcement in the development of compulsive behavior is also emphasized by habit formation studies in OCD. Whilst theories of habit formation in AN and substance dependence have been largely focused on appetitive habits resulting from initially rewarding outcomes, evidence suggests that OCD may be underpinned by the formation of avoidance habits. The compulsions seen in OCD do not seem to develop from an initially rewarding outcome, but rather are typically used to avoid some undesirable consequence (Gillan et al., 2013). These avoidant habits may be related to increased punishment sensitivity reported in OCD (Fullana et al., 2004), in which patients' compulsions reduce distress, and as such may be experienced as an immediate avoidance of punishment (Salkovskis, 1999). If avoidance is important in the development of OCD, it may also have an impact on habit formation in AN and substance dependence. Individuals with $\mathrm{AN}$ have been shown to have both heightened reward and punishment sensitivity, suggested to reflect the avoidant and anxious behaviors seen in $\mathrm{AN}$, which may be used as a means of avoiding increased emotional reactivity to reward and punishment (Jappe et al., 2011). As such, habits in AN may develop as an avoidance of the negative emotions associated with food and weight gain. However, substance dependence is associated with decreased reward and punishment sensitivity (de Ruiter et al., 2009). Whilst compulsive habit behaviors in OCD, appear to begin as the avoidance of something negative, initial drug taking in substance dependence may be much more dependent on increasing the experience of reward. This process is less clear in AN, in which behavior may begin as the pursuit of something rewarding (weight loss) and the avoidance of negative states and anxiety associated with food. 


\section{SUMMARY}

- Whilst AN is often associated with avoidance behaviors, it may in part involve the pursuit of the rewarding aspects of weight loss.

- Theories of substance dependence suggest a shift over time from positive to both positive and negative reinforcement, corresponding to a shift from goal directed to habitual behavior.

- Compulsive behavior in AN may reflect the later stages of substance dependence, in which compulsive habits are driven by both positive and negative reinforcement.

- Negative reinforcement appears to dominate the development of persistent compulsions in OCD.

\section{THE ROLE OF STARVATION IN COMPULSIVE BEHAVIOR}

The evidence reviewed so far suggests that compulsive weight loss behaviors seen in AN are associated with aberrant neurocircuitry and dysfunctional mechanisms of learning and reward that promote compulsive behavior. Crucially, there is evidence that the physiological consequences of starvation promote compulsivity and habit learning, and directly affect positive reinforcement (see Figure 3 for a representation of the effects of starvation on the development of compulsive weight loss habits in AN). For example, in animal models DA (Verhagen et al., 2009b) and serotonin are released in the NAc during starvation-induced hyperactivity, while DA antagonism inhibits anorectic behavior (Verhagen et al., 2009a).

Behavioral evidence in humans suggesting that starvation is associated with the development of compulsive behaviors derives from the Minnesota Experiment (Keys et al., 1950), in which previously healthy males were restricted to half their average food intake for 6 months. These individuals developed food rituals and obsessions, some of which persisted after food restriction ceased, and

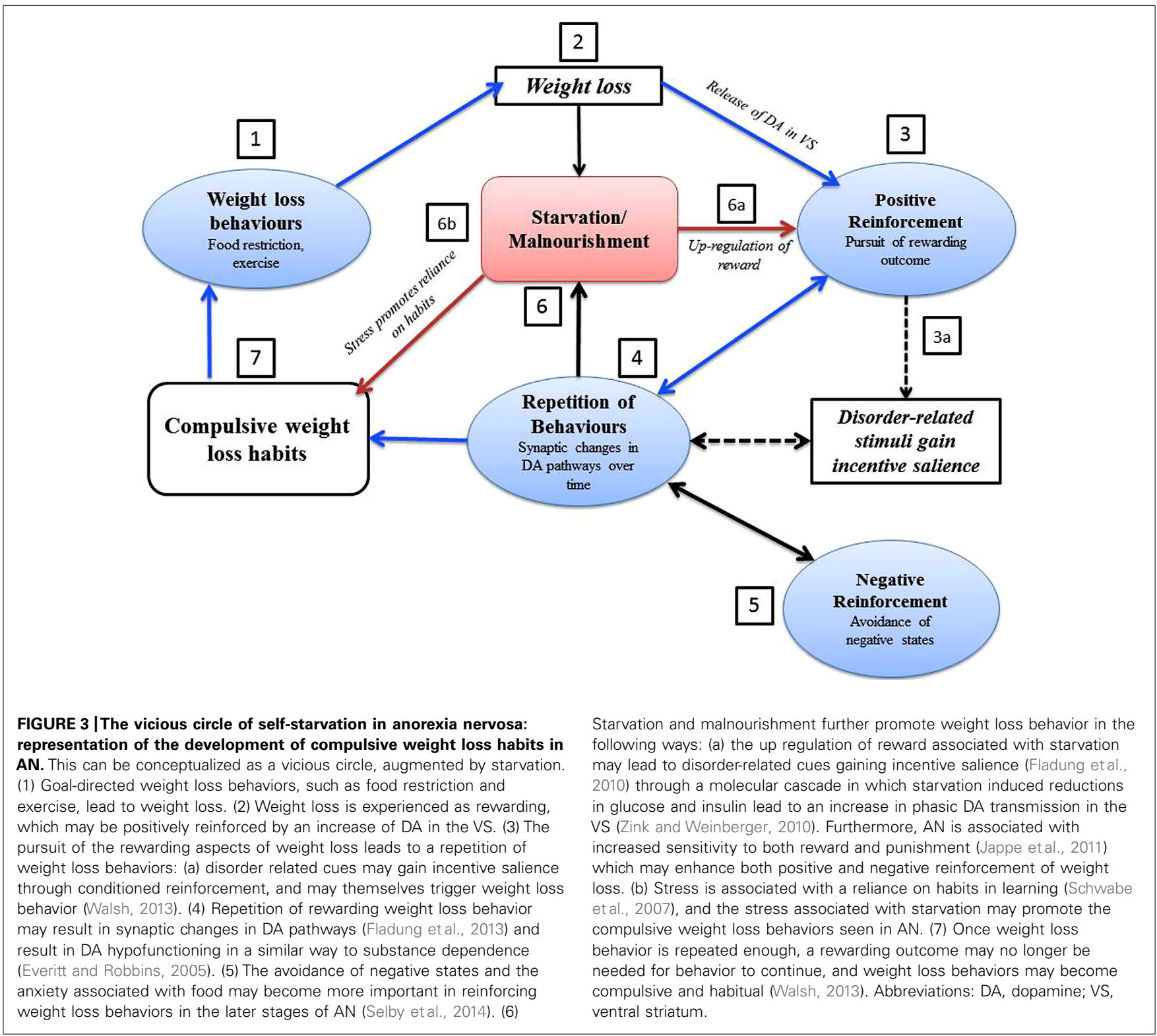


some engaged in binge eating or excessive exercise. They also experienced cognitive impairment and periods of low mood during the study. These individuals were psychologically and physically healthy prior to the experiment, suggesting that these symptoms were due to the food restriction imposed during the experiment. It is possible that starvation effects impact on aberrant neurocircuitry, and dysfunctional mechanisms of learning and reward, to promote compulsive behavior in a vicious circle.

In the animal model of AN, activity based anorexia (ABA) compulsive hyperactivity becomes intrinsically linked to food restriction. Rats on a restricted diet given free access to a running wheel will increase activity to the point of death (Routtenberg and Kuznesof, 1967; Adan et al., 2011). Interestingly, young female rats, as in human AN, show particular susceptibility to this effect (Hancock and Grant, 2009). These rats also show food anticipation activity (FAA), in which an increase in physical activity precedes a meal (Mistlberger, 1994). This increase in activity preceding a meal has also been documented in AN patients (Scheurink et al., 2010). These phenomena have been suggested to reflect an evolutionary advantage of increased activity (foraging) during times of famine (Illius et al., 2002), and appear to show a link between food restriction and increased physical activity. Evidence from the ABA model also suggests a role for DA and serotonin dysfunction in the development of hyperactivity during food restriction. Antagonism of DA receptors is shown to increase food intake and decrease overall physical activity in ABA rats (Verhagen et al., 2009a). Similarly, DA depletion and DA receptor blockade in the NAc decreases FAA (McCullough and Salamone, 1992; Barbano and Cador, 2006). Serotonin has a suppressive effect on food intake (Simansky, 1996) and a decrease in food intake is seen in rats treated with serotonergic agonists (Clifton et al., 2000; Lee et al., 2002). Furthermore, a decrease in 5HT release in the NAc is seen in ABA rats (Verhagen et al., 2009b). Given that AN is associated with altered DA and serotonin levels (see Neurotransmitter Involvement in Compulsivity), this evidence suggests that alterations in these neurotransmitters during the chronic food restriction of AN may increase vulnerability to compulsive exercising.

Food restriction has also been linked to an increase in reward sensitivity. Chronic food restriction, resulting in significant body weight loss, has been shown to increase reward effectiveness when electrically stimulating brain reward circuitry in rats (Fulton et al., 2004). Moreover, body weight correlates with the stimulation threshold for reward, in that a lower body weight leads to a weaker stimulation threshold (Abrahamsen et al., 1995). This effect can also be seen in drug reward. Indeed, chronic food restriction in rats has been found to enhance the rewarding properties of drugs by up-regulating synaptic plasticity in the NAc (Carr, 2007). This increased sensitivity to reward during food restriction may underpin reports of increased salience and attention for disorder-related cues in AN (Fladung et al., 2010, 2013; Giel et al., 2013). Zink and Weinberger (2010) suggest that these disorder-related cues gain incentive salience through a molecular cascade in which starvation induced reductions in glucose and insulin lead to an increase in phasic DA transmission in the VS, a process which conditions associated cues to become highly motivationally salient. This salience increases the likelihood that the behavior will continue, in the same way as drug-associated cues in substance dependence (Zink and Weinberger, 2010). In this way, the neurobiological changes associated with chronic food restriction may enhance the experience of reward in $\mathrm{AN}$, and positively reinforce disorder related compulsions.

The reliance on habits or stimulus-response learning suggested to lead to compulsive behavior may be potentiated in times of stress. Stress is shown to modulate cognitive memory systems in favor of neo-striatum dependent habit systems (Schwabe et al., 2007). Furthermore, participants exposed to an experimental stressor have been shown subsequently to rely on habits during an instrumental learning task, and to show reduced knowledge of the action-outcome associations needed for goal-directed behavior (Schwabe and Wolf, 2009). Food shortage has also been associated with impairments in memory in animals (Plaçais and Preat, 2013), and even brief food restriction is shown to lead to alterations in gene expression of stress hormones (Guarnieri et al., 2012). Thus in AN, psychological and physical stressors associated with the disorder, as well as chronic food restriction, may promote reliance on habits.

\section{SUMMARY}

- Starvation and weight loss is associated with physiological changes that promote compulsive behavior.

- The ABA animal model of AN links food restriction to hyperactivity, and alterations in DA and serotonin are seen in ABA rats.

- Food restriction is associated with an increase in reward sensitivity and positive reinforcement.

- An increase in stress prior to learning is associated with dependence on stimulus-response habits in humans.

\section{IMPLICATIONS FOR TREATMENT}

The behavioral and neurobiological research reviewed suggests that compulsivity is a construct that can be seen in varying degrees across disorders such as AN, OCD, and substance dependence. Conceptualizing compulsive behavior across diagnostic categories opens the way for transdiagnostic treatment strategies. These may target common processes underpinning the compulsivity seen in disorders such as AN, OCD, and substance dependence. The dysregulation of habit formation and reward processes suggested to underpin the development of compulsivity is a potential target for these novel treatment strategies. Treatments targeted at disrupting habitual behavior may have transdiagnostic efficacy.

Functional magnetic resonance imaging findings suggest that the neural areas associated with habit learning and goal directed behavior may be dysfunctional during symptom provocation in AN, providing a potential neural underpinning for an overreliance on habit formation at the expense of goal directed actions. A model of habit formation in AN may thus provide a testable explanation of the development of the persistent compulsive behaviors that develop during the disorder.

Re-patterning habitual behaviors, alongside reversing starvation, has been emphasized as an important component in the treatment of AN (Park et al., 2011, 2012); some concepts previously aimed at behavioral change and habit breaking in other disorders have been translated for use in AN. Given the effects of starvation on neurobiological maintaining mechanisms reviewed 
above, it is likely to be of crucial importance to reverse starvation effects in tandem. Examples of habit breaking strategies are components of cognitive remediation therapy (CRT) and exposure response therapy (ERT). CRT was originally developed for use in the treatment of psychosis, and has also been adapted for use in eating disorders to improve cognitive flexibility and break cognitive habits. Preliminary research into CRT has found improvements in self-reported cognitive flexibility in individuals with AN (Tchanturia et al., 2007a). ERT, which targets conditioned fear responses and conditioned reward, has been used in the treatment of OCD (Foa et al., 2005) and addiction (Kaplan et al., 2011), and some success has been found with graded exposure to food cues in AN, reducing meal-related anxiety post-treatment (Steinglass et al., 2012a).

Given evidence of neural circuitry underpinning compulsivity across disorders, neuromodulatory interventions such as deep brain stimulation (DBS), and the less invasive repetitive transcranial magnetic stimulation (rTMS), may benefit from common neural targets for treatment across disorders. DBS is a reversible, adjustable neurosurgical treatment that involves implanting electrodes that send electrical impulses to chosen locations in the brain (Rauch, 2003). DBS has been effective in the treatment of OCD when targeting the NAc, and is suggested to normalize excessive connectivity between the NAc and PFC (Figee et al., 2013). The reported efficacy of DBS to the NAc in OCD and addictions (Kuhn et al., 2007; Liu et al., 2008; Muller et al., 2009; Denys et al., 2010; Figee et al., 2013) is consistent with the involvement of fronto-striatal circuits across compulsive disorders. Both animal studies (Liu et al., 2008; Henderson et al., 2010) and DBS in substance dependent individuals (Kuhn et al., 2007; Muller et al., 2009) have found decreases in addictive behaviors when stimulating the NAc. Given that the NAc area is suggested to be involved in the transition from voluntary to compulsive drug use (Everitt and Robbins, 2005), it is possible that NAc stimulation may disrupt this process and thereby reduce compulsive behaviors. Case reports of DBS to the NAc in AN patients have also reported symptom alleviation both in the presence and absence of comorbid OCD (Wu et al., 2012; Lipsman et al., 2013; McLaughlin et al., 2013). RTMS, a non-invasive brain stimulation technique targeting the dorsolateral prefrontal cortex, has been shown to have some efficacy across disorders, reducing cravings and consumption in substance dependence (Barr et al., 2011), decreasing compulsions and obsessions in OCD (Blom et al., 2011), and reducing anxiety and potentially the urge to exercise in AN (Van den Eynde et al., 2013).

Novel pharmacological treatments targeting addictive or compulsive behaviors may also prove useful in the treatment of compulsivity across disorders. The DA dysfunction seen in many compulsive disorders may be a potential target for pharmacological intervention. Given animal and human evidence that DA modulation of glutaminergic transmission plays a role in reward and reinforcement, glutaminergic medications may also prove useful in compulsive disorders such as addictions (Kenny and Markou, 2004). The use of drugs that target GABA and glutamate pathways has shown some benefit in the treatment of substance use disorders (Clarke et al., 2004; Olive et al., 2012), binge eating (Guardia et al., 2011), and OCD (Pittenger et al., 2011), and may also prove beneficial in other disorders in which compulsive behavior develops.

\section{CONCLUDING REMARKS}

Conceptualizing compulsivity as a transdiagnostic concept, uniting separately classified disorders through common pathological processes, may help in the development of novel behavioral and neural interventions, which could be effective across diagnostic boundaries. These are urgently needed, given the poor outcome and limited evidence base for treatment of AN, especially in adulthood. Future research should aim to test this concept directly, for example by looking at the behavioral and neural basis of habit formation in relation to compulsivity in AN, OCD, and substance dependence, as well as other disorders that exhibit compulsive behaviors.

\section{ACKNOWLEDGMENTS}

Lauren Godier is funded by an MRC Ph.D. Studentship. Rebecca Park is funded by an HEFCE Clinical Senior Lectureship award.

\section{REFERENCES}

Abrahamsen, G. C., Berman, Y., and Carr, K. D. (1995). Curve-shift analysis of self-stimulation in food-restricted rats: relationship between daily meal, plasma corticosterone and reward sensitization. Brain Res. 695, 186-194. doi: 10.1016/0006-8993(95)00764-H

Adan, R. A., Hillebrand, J. J., Danner, U. N., Cardona Cano, S., Kas, M. J., and Verhagen, L. A. (2011). Neurobiology driving hyperactivity in activity-based anorexia. Curr. Top. Behav. Neurosci. 6, 229-250. doi: 10.1007/7854_2010_77

Allegre, B., Souville, M., Therme, P., and Griffiths, M. (2006). Definitions and measures of exercise dependence. Addict. Res. Theory 14, 631-646. doi: 10.1080/16066350600903302

American Psychiatric Association. (2013). Diagnostic and Statistical Manual of Mental Disorders, 5th Edn. (Arlington, VA: American Psychiatric Publishing).

Anderluh, M., Tchanturia, K., Rabe-Hesketh, S., Collier, D., and Treasure, J. (2008). Lifetime course of eating disorders: design and validity testing of a new strategy to define the eating disorders phenotype. Behav. Res. Ther. 46, 757-765. doi: 10.1017/S0033291708003292

Ansell, E. B., Pinto, A., Crosby, R. D., Becker, D. F., Anez, L. M., Paris, M., et al. (2010). The prevalence and structure of obsessive-compulsive personality disorder in Hispanic psychiatric outpatients. J. Behav. Ther. Exp. Psychiatry 41, 275-281. doi: 10.1016/j.jbtep.2010.02.005

Arcelus, J., Mitchell, A. J., Wales, J., and Nielsen, S. (2011). Mortality rates in patients with anorexia nervosa and other eating disorders. A meta-analysis of 36 studies. Arch. Gen. Psychiatry 68, 724-731. doi: 10.1001/archgenpsychiatry. 2011.74

Bailer, U. F., Frank, G. K., Henry, S. E., Price, J. C., Meltzer, C. C., Mathis, C. A., et al. (2007). Exaggerated 5-HT1A but normal 5-HT2A receptor activity in individuals ill with anorexia nervosa. Biol. Psychiatry 61, 1090-1099. doi: 10.1016/j.biopsych.2006.07.018

Bailer, U. F., Frank, G. K., Price, J. C., Meltzer, C. C., Becker, C., Mathis, C. A., et al. (2013). Interaction between serotonin transporter and dopamine D2/D3 receptor radioligand measures is associated with harm avoidant symptoms in anorexia and bulimia nervosa. Psychiatry Res. 211, 160-168. doi: 10.1016/j.pscychresns.2012.06.010

Bailer, U. F., Narendran, R., Frankle, W. G., Himes, M. L., Duvvuri, V., Mathis, C. A., et al. (2012). Amphetamine induced dopamine release increases anxiety in individuals recovered from anorexia nervosa. Int. J. Eat. Disord. 45, 263-271. doi: 10.1002/eat.20937

Baker, J. H., Thornton, L. M., Strober, M., Brandt, H., Crawford, S., Fichter, M. M., etal. (2013). Temporal sequence of comorbid alcohol use disorder and anorexia nervosa. Addict. Behav. 38, 1704-1709. doi: 10.1016/j.addbeh.2012. 10.005

Balleine, B. W., and O'Doherty, J. P. (2010). Human and rodent homologies in action control: corticostriatal determinants of goal-directed and habitual action. Neuropsychopharmacology 35, 48-69. doi: 10.1038/npp.2009.131 
Barbano, M. F., and Cador, M. (2006). Differential regulation of the consummatory, motivational and anticipatory aspects of feeding behavior by dopaminergic and opioidergic drugs. Neuropsychopharmacology 31, 1371-1381. doi: 10.1038/sj.npp.1300908

Barbarich-Marsteller, N. C., Foltin, R. W., and Walsh, B. T. (2011). Does anorexia nervosa resemble an addiction? Curr. Drug Abuse Rev. 4, 197-200. doi $10.2174 / 1874473711104030197$

Bargh, J. A. (1989). "Conditional automaticity: varieties of automatic influence in social perception and cognition," in Unintended Thought, Vol. 3, eds J. S. Uleman and J. A. Bargh (New York, NY: Guilford Press), 3-51.

Barr, M. S., Farzan, F., Wing, V. C., George, T. P., Fitzgerald, P. B., and Daskalakis, Z. J. (2011). Repetitive transcranial magnetic stimulation and drug addiction. Int. Rev. Psychiatry 23, 454-466. doi: 10.3109/09540261.2011. 618827

Bassareo, V., and Di Chiara, G. (1999). Differential responsiveness of dopamine transmission to food-stimuli in nucleus accumbens shell/core compartments. Neuroscience 89, 637-641. doi: 10.1016/S0306-4522(98)00583-1

Belin, D., Economidou, D., Pelloux, Y., and Everitt, B. (2011). "Habit formation and compulsion," in Animal Models of Drug Addiction, ed. M. C. Olmstead (New York NY: Humana Press), 337-378.

Bellodi, L. L., Cavallini, M. C. M., Bertelli, S. S., Chiapparino, D. D., Riboldi, C. C., and Smeraldi, E. E. (2001). Morbidity risk for obsessive-compulsive spectrum disorders in first-degree relatives of patients with eating disorders. Am. J. Psychiatry 158, 563-569. doi: 10.1176/appi.ajp.158.4.563

Beninger, R., and Gerdjikov, T. (2005). "Dopamine-glutamate interactions in reward-related incentive learning," in Dopamine and Glutamate in Psychiatric Dis orders, eds W. Schmidt and M. A. Reith (Totowa, NJ: Humana Press), 319-354. doi: 10.1007/978-1-59259-852-6_14

Bergen, A. W., Yeager, M., Welch, R. A., Haque, K., Ganjei, J. K., van den Bree, M. B., et al. (2005). Association of multiple DRD2 polymorphisms with anorexia nervosa. Neuropsychopharmacology 30, 1703-1710. doi: 10.1038/sj.npp.1300719

Berkman, N. D., Lohr, K. N., and Bulik, C. M. (2007). Outcomes of eating disorders: a systematic review of the literature. Int. J. Eat. Disord. 40, 293-309. doi: 10.1002/eat.20369

Berlin, H. A., Rolls, E. T., and Kischka, U. (2004). Impulsivity, time perception, emotion and reinforcement sensitivity in patients with orbitofrontal cortex lesions. Brain 127, 1108-1126. doi: 10.1093/brain/awh135

Blom, R. M., Figee, M., Vulink, N., and Denys, D. (2011). Update on repetitive transcranial magnetic stimulation in obsessive-compulsive disorder: different targets. Curr. Psychiatry Rep. 13, 289-294. doi: 10.1007/s11920-011-0205-3

Boulougouris, V., Glennon, J. C., and Robbins, T. W. (2008). Dissociable effects of selective 5-HT2A and 5-HT2C receptor antagonists on serial spatial reversal learning in rats. Neuropsychopharmacology 33, 2007-2019. doi: 10.1038/sj.npp.1301584

Brewer, J. A., and Potenza, M. N. (2008). The neurobiology and genetics of impulse control disorders: relationships to drug addictions. Biochem. Pharmacol. 75, 6375. doi: 10.1016/j.bcp.2007.06.043

Broft, A., Shingleton, R., Kaufman, J., Liu, F., Kumar, D., Slifstein, M., et al. (2012) Striatal dopamine in bulimia nervosa: a PET imaging study. Int. J. Eat. Disord. 45, 648-656. doi: 10.1002/eat.20984

Bühren, K., Mainz, V., Herpertz-Dahlmann, B., Schäfer, K., Kahraman-Lanzerath, B., Lente, C., et al. (2012). Cognitive flexibility in juvenile anorexia nervosa patients before and after weight recovery. J. Neural. Transm. 119, 1047-1057. doi: 10.1007/s00702-012-0821-z

Carli, M., Baviera, M., Invernizzi, R. W., and Balducci, C. (2006). Dissociable contribution of 5-HT1A and 5-HT2A receptors in the medial prefrontal cortex to different aspects of executive control such as impulsivity and compulsive perseveration in rats. Neuropsychopharmacology 31, 757-767. doi: 10.1038/sj.npp.1300893

Carr, K. D. (2007). Chronic food restriction: enhancing effects on drug reward and striatal cell signaling. Physiol. Behav. 91, 459-472. doi: 10.1016/j.physbeh.2006.09.021

Casa. (2003). Food for Thought: Substance Abuse and Eating Disorders. New York: The National Centre on Addiction and Substance Use (CASA) at Columbia University. Castro-Fornieles, J., Deulofeu, R., Baeza, I., Casula, V., Saura, B., Lazaro, L., et al. (2008). Psychopathological and nutritional correlates of plasma homovanillic acid in adolescents with anorexia nervosa. J. Psychiatr. Res. 42, 213-220. doi: 10.1016/j.jpsychires.2006.10.009
Cavedini, P., Bassi, T., Zorzi, C., and Bellodi, L. (2004). The advantages of choosing antiobsessive therapy according to decision-making functioning. J. Clin. Psychopharmacol. 24, 628-631. doi: 10.1097/01.jcp.0000144889.51072.03

Chamberlain, S. R., Menzies, L., Hampshire, A., Suckling, J., Fineberg, N. A., Del Campo, N., et al. (2008). Orbitofrontal dysfunction in patients with obsessivecompulsive disorder and their unaffected relatives. Science 321, 421-422. doi: $10.1126 /$ science. 1154433

Clarke, H. F., Dalley, J. W., Crofts, H. S., Robbins, T. W., and Roberts, A. C. (2004). Cognitive inflexibility after prefrontal serotonin depletion. Science 304, 878-880. doi: 10.1126/science.1094987

Clarke, H. F., Robbins, T. W., and Roberts, A. C. (2008). Lesions of the medial striatum in monkeys produce perseverative impairments during reversal learning similar to those produced by lesions of the orbitofrontal cortex. J. Neurosci. 28, 10972-10982. doi: 10.1523/JNEUROSCI.1521-08.2008

Clifton, P. G., Lee, M. D., and Dourish, C. T. (2000). Similarities in the action of Ro 60-0175, a 5-HT2C receptor agonist and d-fenfluramine on feeding patterns in the rat. Psychopharmacology (Berl.) 152, 256-267. doi: 10.1007/s002130000504

Cools, R., Altamirano, L., and D'Esposito, M. (2006). Reversal learning in Parkinson's disease depends on medication status and outcome valence. Neuropsychologia 44, 1663-1673. doi: 10.1016/j.neuropsychologia.2006.03.030

Cowdrey, F. A., Finlayson, G., and Park, R. J. (2013). Liking compared with wanting for high- and low-calorie foods in anorexia nervosa: aberrant food reward even after weight restoration. Am. J. Clin. Nutr. 97, 463-470. doi: 10.3945/ajcn.112.046011

Cowdrey, F. A., Park, R. J., Harmer, C. J., and Mccabe, C. (2011). Increased neural processing of rewarding and aversive food stimuli in recovered anorexia nervosa. Biol. Psychiatry 70, 736-743. doi: 10.1016/j.biopsych.2011.05.028

Dalle Grave, R., Calugi, S., and Marchesini, G. (2008). Compulsive exercise to control shape or weight in eating disorders: prevalence, associated features, and treatment outcome. Compr. Psychiatry 49, 346-352. doi: 10.1016/j.comppsych.2007.12.007

Dalley, J. W., Everitt, B. J., and Robbins, T. W. (2011). Impulsivity, compulsivity, and top-down cognitive control. Neuron 69, 680-694. doi: 10.1016/j.neuron.2011.01.020

Davis, C., Patte, K., Curtis, C., and Reid, C. (2010). Immediate pleasures and future consequences. A neuropsychological study of binge eating and obesity. Appetite 54, 208-213. doi: 10.1016/j.appet.2009.11.002

Daw, N. D., Niv, Y., and Dayan, P. (2005). Uncertainty-based competition between prefrontal and dorsolateral striatal systems for behavioral control. Nat. Neurosci. 8, 1704-1711. doi: 10.1038/nn1560

de Ruiter, M. B., Veltman, D. J., Goudriaan, A. E., Oosterlaan, J., Sjoerds, Z., and Van Den Brink, W. (2009). Response perseveration and ventral prefrontal sensitivity to reward and punishment in male problem gamblers and smokers. Neuropsychopharmacology 34, 1027-1038. doi: 10.1038/npp.2008.175

de Wit, S., Watson, P., Harsay, H. A., Cohen, M. X., Van De Vijver, I., and Ridderinkhof, K. R. (2012). Corticostriatal connectivity underlies individual differences in the balance between habitual and goal-directed action control. J. Neurosci. 32, 12066-12075. doi: 10.1523/JNEUROSCI.108812.2012

Denys, D., Mantione, M., Figee, M., Van Den Munckhof, P., Koerselman, F., Westenberg, H., et al. (2010). Deep brain stimulation of the nucleus accumbens for treatment-refractory obsessive-compulsive disorder. Arch. Gen. Psychiatry 67, 1061-1068. doi: 10.1001/archgenpsychiatry.2010.122

Deroche-Gamonet, V. R., Belin, D., and Piazza, P. V. (2004). Evidence for addictionlike behavior in the rat. Science 305, 1014-1017. doi: 10.1126/science.1099020

Dias, R., Robbins, T. W., and Roberts, A. C. (1996). Dissociation in prefrontal cortex of affective and attentional shifts. Nature 380,69-72. doi: 10.1038/380069a0

Dickinson, A., Wood, N., and Smith, J. W. (2002). Alcohol seeking by rats: action or habit? Q. J. Exp. Psychol. B 55, 331-348. doi: 10.1080/0272499024400016

Everitt, B. J., and Robbins, T. W. (2005). Neural systems of reinforcement for drug addiction: from actions to habits to compulsion. Nat. Neurosci. 8, 1481-1489. doi: $10.1038 / \mathrm{nn} 1579$

Evers, E. A., Cools, R., Clark, L., Van Der Veen, F. M., Jolles, J., Sahakian, B. J., et al. (2005). Serotonergic modulation of prefrontal cortex during negative feedback in probabilistic reversal learning. Neuropsychopharmacology 30, 1138-1147. doi: 10.1038/sj.npp. 1300663

Fairburn, C. G., Cooper, Z., and Shafran, R. (2003). Cognitive behaviour therapy for eating disorders: a "transdiagnostic" theory and treatment. Behav. Res. Ther. 41, 509-528. doi: 10.1016/S0005-7967(02)00088-8 
Figee, M., Luigjes, J., Smolders, R., Valencia-Alfonso, C.-E., Van Wingen, G., De Kwaasteniet, B., et al. (2013). Deep brain stimulation restores frontostriatal network activity in obsessive-compulsive disorder. Nat. Neurosci. 16, 386-387. doi: 10.1038/nn.3344

Fineberg, N. A., Potenza, M. N., Chamberlain, S. R., Berlin, H. A., Menzies, L., Bechara, A., et al. (2010). Probing compulsive and impulsive behaviors, from animal models to endophenotypes: a narrative review. Neuropsychopharmacology 35, 591-604. doi: 10.1038/npp.2009.185

Fladung, A. K., Gron, G., Grammer, K., Herrnberger, B., Schilly, E., Grasteit, S., et al. (2010). A neural signature of anorexia nervosa in the ventral striatal reward system. Am. J. Psychiatry 167, 206-212. doi: 10.1176/appi.ajp.2009.09010071

Fladung, A. K., Schulze, U. M. E., Schöll, F., Bauer, K., and Grön, G. (2013). Role of the ventral striatum in developing anorexia nervosa. Transl. Psychiatry 3:e315. doi: $10.1038 /$ tp. 2013.88

Fletcher, P. J., Grottick, A. J., and Higgins, G. A. (2002). Differential effects of the 5-HT2A receptor antagonist M100,907 and the 5-HT2C receptor antagonis SB242,084 on cocaine-induced locomotor activity, cocaine self-administration and cocaine-induced reinstatement of responding. Neuropsychopharmacology 27, 576-586. doi: 10.1016/S0893-133X(02)00342-1

Foa, E. B., Liebowitz, M. R., Kozak, M. J., Davies, S., Campeas, R., Franklin, M. E., et al. (2005). Randomized, placebo-controlled trial of exposure and ritual prevention, clomipramine, and their combination in the treatment of obsessive-compulsive disorder. Am. J. Psychiatry 162, 151-161. doi: 10.1176/appi.ajp.162.1.151

Fontenelle, L., Marques, C., Engelhardt, E., and Versiani, M. (2001). Impaired set-shifting ability and therapeutic response in obsessive-compulsive disorder. $J$. Neuropsychiatry Clin. Neurosci. 13, 508-510. doi: 10.1176/appi.neuropsych.13. 4.508

Fornari, V., Kaplan, M., Sandberg, D. E., Matthews, M., Skolnick, N., and Katz, J. L. (1992). Depressive and anxiety disorders in anorexia nervosa and bulimia nervosa. Int. J. Eat. Disord. 12, 21-29. doi: 10.1002/1098-108X(199207)12:1<21::AIDEAT2260120104>3.0.CO;2-Y

Frank, G. K., Bailer, U. F., Henry, S. E., Drevets, W., Meltzer, C. C., Price, J. C., et al. (2005). Increased dopamine D2/D3 receptor binding after recovery from anorexia nervosa measured by positron emission tomography and $\left[{ }^{11} \mathrm{C}\right]$ raclopride. Biol. Psychiatry 58, 908-912. doi: 10.1016/j.biopsych.2005.05.003

Frank, G. K., Shott, M. E., Hagman, J. O., and Mittal, V. A. (2013). Alterations in brain structures related to taste reward circuitry in Ill and recovered anorexia nervosa and in bulimia nervosa. Am. J. Psychiatry 2013, 1152-1160. doi 10.1176/appi.ajp.2013.12101294

Franklin, T. R., Acton, P. D., Maldjian, J. A., Gray, J. D., Croft, J. R., Dackis, C. A., et al. (2002). Decreased gray matter concentration in the insular, orbitofrontal, cingulate, and temporal cortices of cocaine patients. Biol. Psychiatry 51, 134-142. doi: 10.1016/S0006-3223(01)01269-0

Fullana, M. A., Mataix-Cols, D., Caseras, X., Alonso, P., Manuel Menchon, J., Vallejo, J., et al. (2004). High sensitivity to punishment and low impulsivity in obsessivecompulsive patients with hoarding symptoms. Psychiatry Res. 129, 21-27. doi: 10.1016/j.psychres.2004.02.017

Fulton, S., Richard, D., Woodside, B., and Shizgal, P. (2004). Food restriction and leptin impact brain reward circuitry in lean and obese Zucker rats. Behav. Brain Res. 155, 319-329. doi: 10.1016/j.bbr.2004.05.021

Gearhardt, A. N., Yokum, S., Orr, P. T., Stice, E., Corbin, W. R., and Brownell, K. D. (2011). Neural correlates of food addiction. Arch. Gen. Psychiatry 68, 808-816. doi: 10.1001/archgenpsychiatry.2011.32

Giel, K. E., Kullmann, S., Preißl, H., Bischoff, S. C., Thiel, A., Schmidt, U., et al. (2013). Understanding the reward system functioning in anorexia nervosa: crucial role of physical activity. Biol. Psychol. 94, 575-581. doi: 10.1016/j.biopsycho.2013.10.004

Gillan, C. M., Morein-Zamir, S., Urcelay, G. P., Sule, A., Voon, V., Apergis-Schoute, A. M., et al. (2013). Enhanced avoidance habits in obsessive-compulsive disorder. Biol. Psychiatry 3223, 145-145. doi: 10.1016/j.biopsych.2013.02.002

Gillan, C. M., Papmeyer, M., Morein-Zamir, S., Sahakian, B. J., Fineberg, N. A., Robbins, T. W., et al. (2011). Disruption in the balance between goal-directed behavior and habit learning in obsessive-compulsive disorder. Am. J. Psychiatry 168, 718-726. doi: 10.1176/appi.ajp.2011.10071062

Godart, N. T., Flament, M. F., Perdereau, F., and Jeammet, P. (2002). Comorbidity between eating disorders and anxiety disorders: a review. Int. J. Eat. Disord. 32, 253-270. doi: 10.1002/eat.10096
Graybiel, A. M. (2008). Habits, rituals, and the evaluative brain. Annu. Rev. Neurosci. 31, 359-387. doi: 10.1146/annurev.neuro.29.051605.112851

Gross-Isseroff, R., Cohen, R., Sasson, Y., Voet, H., and Zohar, J. (2004). Serotonergic dissection of obsessive compulsive symptoms: a challenge study with m-chlorophenylpiperazine and sumatriptan. Neuropsychobiology 50, 200-205. doi: 10.1159/000079970

Guardia, D., Rolland, B., Karila, L., and Cottencin, O. (2011). GABAergic and glutamatergic modulation in binge eating: therapeutic approach. Curr. Pharm. Des. 17, 1396-1409. doi: 10.2174/138161211796150828

Guarnieri, D. J., Brayton, C. E., Richards, S. M., Maldonado-Aviles, J., Trinko, J. R., Nelson, J., et al. (2012). Gene profiling reveals a role for stress hormones in the molecular and behavioral response to food restriction. Biol. Psychiatry 71, 358-365. doi: 10.1016/j.biopsych.2011.06.028

Halmi, K. A., Eckert, E., Marchi, P., Sampugnaro, V., Apple, R., and Cohen, J. (1991). Comorbidity of psychiatric diagnoses in anorexia nervosa. Arch. Gen. Psychiatry 48, 712-718. doi: 10.1001/archpsyc.1991.01810320036006

Hampshire, A., and Owen, A. M. (2006). Fractionating attentional control using event-related fMRI. Cereb. Cortex 16, 1679-1689. doi: 10.1093/cercor/bhj116

Hancock, S., and Grant, V. (2009). Early maternal separation increases symptoms of activity-based anorexia in male and female rats. J. Exp. Psychol. Anim. Behav. Process. 35, 394-406. doi: 10.1037/a0014736

Henderson, M. B., Green, A. I., Bradford, P. S., Chau, D. T., Roberts, D. W., and Leiter, J. C. (2010). Deep brain stimulation of the nucleus accumbens reduces alcohol intake in alcohol-preferring rats. Neurosurg. Focus 29:E12. doi: 10.3171/2010.4.FOCUS10105

Holderness, C. C., Brooks-Gunn, J., and Warren, M. P. (1994). Co-morbidity of eating disorders and substance abuse review of the literature. Int. J. Eat. Disord. 16, 1-34. doi: 10.1002/1098-108X(199407)16:1<1::AID-EAT2260160102>3.0. $\mathrm{CO} ; 2-\mathrm{T}$

Hollander, E., Decaria, C., Nitescu, A., Cooper, T., Stover, B., Gully, R., et al. (1991). Noradrenergic function in obsessive-compulsive disorder: behavioral and neuroendocrine responses to clonidine and comparison to healthy controls. Psychiatry Res. 37, 161-177. doi: 10.1016/0165-1781(91)90073-X

Hollander, E., and Rosen, J. (2000). Impulsivity. J. Psychopharmacol. 14, S39-S44.

Holliday, J., Tchanturia, K., Landau, S., Collier, D., and Treasure, J. (2005). Is impaired set-shifting an endophenotype of anorexia nervosa? Am. J. Psychiatry 162, 2269-2275. doi: 10.1176/appi.ajp.162.12.2269

Holtkamp, K., Muller, B., Heussen, N., Remschmidt, H., and Herpertz-Dahlmann, B. (2005). Depression, anxiety, and obsessionality in long-term recovered patients with adolescent-onset anorexia nervosa. Eur. Child Adolesc. Psychiatry 14, 106110. doi: 10.1007/s00787-005-0431-5

Hou, J., Song, L., Zhang, W., Wu, W., Wang, J., Zhou, D., et al. (2013). Morphologic and functional connectivity alterations of corticostriatal and default mode network in treatment-naïve patients with obsessive-compulsive disorder. PLoS One 8:e83931. doi: 10.1371/journal.pone.0083931

Illius, A. W., Tolkamp, B. J., and Yearsley, J. (2002). The evolution of the control of food intake. Proc. Nutr. Soc. 61, 465-472. doi: 10.1079/PNS2002179

Ito, R., Dalley, J. W., Howes, S. R., Robbins, T. W., and Everitt, B. J. (2000). Dissociation in conditioned dopamine release in the nucleus accumbens core and shell in response to cocaine cues and during cocaine-seeking behavior in rats. J. Neurosci. 20, 7489-7495.

Ito, R., Dalley, J. W., Robbins, T. W., and Everitt, B. J. (2002). Dopamine release in the dorsal striatum during cocaine-seeking behavior under the control of a drug-associated cue. J. Neurosci. 22, 6247-6253.

Izquierdo, A., and Jentsch, J. D. (2012). Reversal learning as a measure of impulsive and compulsive behavior in addictions. Psychopharmacology 219, 607-620. doi: 10.1007/s00213-011-2579-7

Jamain, S., Betancur, C., Quach, H., Philippe, A., Fellous, M., Giros, B., et al. (2002). Linkage and association of the glutamate receptor 6 gene with autism. Mol. Psychiatry 7, 302-310. doi: 10.1038/si.mp.4000979

Jappe, L. M., Frank, G. K., Shott, M. E., Rollin, M. D., Pryor, T., Hagman, J. O., et al. (2011). Heightened sensitivity to reward and punishment in anorexia nervosa. Int. J. Eat. Disord. 44, 317-324. doi: 10.1002/eat.20815

Kalivas, P. W., and Volkow, N. D. (2005). The neural basis of addiction: a pathology of motivation and choice. Am. J. Psychiatry 162, 1403-1413. doi: 10.1176/appi.ajp.162.8.1403

Kaplan, G. B., Heinrichs, S. C., and Carey, R. J. (2011). Treatment of addiction and anxiety using extinction approaches: neural mechanisms and 
their treatment implications. Pharmacol. Biochem. Behav. 97, 619-625. doi: 10.1016/j.pbb.2010.08.004

Kaye, W. H., Frank, G. K., Bailer, U. F., and Henry, S. E. (2005a). Neurobiology of anorexia nervosa: clinical implications of alterations of the function of serotonin and other neuronal systems. Int. J. Eat. Disord. 37, S15-S19; discussion S20-S11. doi: 10.1002/eat.20109

Kaye, W. H., Frank, G. K., Bailer, U. F., Henry, S. E., Meltzer, C. C., Price, J. C., et al. (2005b). Serotonin alterations in anorexia and bulimia nervosa: new insights from imaging studies. Physiol. Behav. 85, 73-81. doi: 10.1016/j.physbeh.2005.04.013

Kaye, W. H., Frank, G. K., and McConaha, C. (1999). Altered dopamine activity after recovery from restricting-type anorexia nervosa. Neuropsychopharmacology 21, 503-506. doi: 10.1016/S0893-133X(99)00053-6

Kaye, W. H., Wierenga, C. E., Bailer, U. F., Simmons, A. N., Wagner, A., and BischoffGrethe, A. (2013a). Does a shared neurobiology for foods and drugs of abuse contribute to extremes of food ingestion in anorexia and bulimia nervosa? Biol. Psychiatry 73, 836-842. doi: 10.1016/j.biopsych.2013.01.002

Kaye, W. H., Wierenga, C. E., Bailer, U. F., Simmons, A. N., and BischoffGrethe, A. (2013b). Nothing tastes as good as skinny feels: the neurobiology of anorexia nervosa. Trends Neurosci. 36, 110-120. doi: 10.1016/j.tins.2013. 01.003

Kenny, P. J. (2011). Reward mechanisms in obesity: new insights and future directions. Neuron 69, 664-679. doi: 10.1016/j.neuron.2011.02.016

Kenny, P. J., and Markou, A. (2004). The ups and downs of addiction: role of metabotropic glutamate receptors. Trends Pharmacol. Sci. 25, 265-272. doi: 10.1016/j.tips.2004.03.009

Keys, A., Brozek, J., Henschel, A., Mickelsen, O., and Taylor, H. L. (1950). The Biology of Human Starvation. Oxford: University of Minnesota Press.

Kirby, L. G., Zeeb, F. D., and Winstanley, C. A. (2011). Contributions of serotonin in addiction vulnerability. Neuropharmacology 61, 421-432. doi: 10.1016/j.neuropharm.2011.03.022

Koob, G. F., and Volkow, N. D. (2010). Neurocircuitry of addiction. Neuropsychopharmacology 35, 217-238. doi: 10.1038/npp.2009.110

Kuhn, J., Lenartz, D., Huff, W., Lee, S., Koulousakis, A., Klosterkoetter, J., et al. (2007). Remission of alcohol dependency following deep brain stimulation of the nucleus accumbens: valuable therapeutic implications? J. Neurol. Neurosurg Psychiatry 78, 1152-1153. doi: 10.1136/jnnp.2006.113092

Lawrence, N. S., Wooderson, S., Mataix-Cols, D., David, R., Speckens, A., and Phillips, M. L. (2006). Decision making and set shifting impairments are associated with distinct symptom dimensions in obsessive-compulsive disorder. Neuropsychology 20, 409-419. doi: 10.1037/0894-4105.20.4.409

Lee, M. D., Kennett, G. A., Dourish, C. T., and Clifton, P. G. (2002). 5-HT1B receptors modulate components of satiety in the rat: behavioural and pharmacological analyses of the selective serotonin1B agonist CP-94,253. Psychopharmacology (Berl.) 164, 49-60. doi: 10.1007/s00213-002-1162-7

Lilenfeld, L. R., Kaye, W. H., Greeno, C. G., Merikangas, K. R., Plotnicov, K., Pollice, C., et al. (1998). A controlled family study of anorexia nervosa and bulimia nervosa: psychiatric disorders in first-degree relatives and effects of proband comorbidity. Arch. Gen. Psychiatry 55, 603-610. doi: 10.1001/archpsyc.55.7.603

Lilenfeld, L. R. R., Wonderlich, S., Riso, L. P., Crosby, R., and Mitchell, J. (2006). Eating disorders and personality: a methodological and empirical review. Clin. Psychol. Rev. 26, 299-320. doi: 10.1016/j.cpr.2005.10.003

Lipsman, N., Woodside, D. B., Giacobbe, P., Hamani, C., Carter, J. C., Norwood, S. J., et al. (2013). Subcallosal cingulate deep brain stimulation for treatmentrefractory anorexia nervosa: a phase 1 pilot trial. Lancet 381, 1361-1370. doi: 10.1016/s0140-6736(12)62188-6

Liu, H. Y., Jin, J., Tang, J. S., Sun, W. X., Jia, H., Yang, X. P., et al. (2008). Chronic deep brain stimulation in the rat nucleus accumbens and its effect on morphine reinforcement. Addict. Biol. 13, 40-46. doi: 10.1111/j.1369-1600.2007.00088.x

Mas, S., Plana, M. T., Castro-Fornieles, J., Gasso, P., Lafuente, A., Moreno, E., et al. (2013). Common genetic background in anorexia nervosa and obsessive compulsive disorder: preliminary results from an association study. J. Psychiatric Res. 47, 747-754. doi: 10.1016/j.jpsychires.2012.12.015

McCullough, L. D., and Salamone, J. D. (1992). Involvement of nucleus accumbens dopamine in the motor activity induced by periodic food presentation: a microdialysis and behavioral study. Brain Res. 592, 29-36. doi: 10.1016/00068993(92)91654-W

McLaughlin, N. C., Didie, E. R., Machado, A. G., Haber, S. N., Eskandar, E. N., and Greenberg, B. D. (2013). Improvements in anorexia symptoms after deep brain stimulation for intractable obsessive-compulsive disorder. Biol. Psychiatry 73, e29-e31. doi: 10.1016/j.biopsych.2012.09.015

Menzies, L., Chamberlain, S. R., Laird, A. R., Thelen, S. M., Sahakian, B. J., and Bullmore, E. T. (2008). Integrating evidence from neuroimaging and neuropsychological studies of obsessive-compulsive disorder: the orbitofronto-striatal model revisited. Neurosci. Biobehav. Rev. 32, 525-549. doi: 10.1016/j.neubiorev.2007.09.005

Meunier, D., Ersche, K. D., Craig, K. J., Fornito, A., Merlo-Pich, E., Fineberg, N. A., et al. (2012). Brain functional connectivity in stimulant drug dependence and obsessive-compulsive disorder. Neuroimage 59, 1461-1468. doi: 10.1016/j.neuroimage.2011.08.003

Meyer, C., Taranis, L., Goodwin, H., and Haycraft, E. (2011). Compulsive exercise and eating disorders. Eur. Eat. Disord. Rev. 19, 174-189. doi: 10.1002/erv.1122

Miles, F. J., Everitt, B. J., and Dickinson, A. (2003). Oral cocaine seeking by rats: action or habit? Behav. Neurosci. 117, 927-938. doi: 10.1037/0735-7044.117.5.927 Mistlberger, R. E. (1994). Circadian food-anticipatory activity: formal models and physiological mechanisms. Neurosci. Biobehav. Rev. 18, 171-195. doi: 10.1016/0149-7634(94)90023-X

Miszkiel, J., Filip, M., and Przegalinski, E. (2011). Role of serotonin 5-HT1B receptors in psychostimulant addiction. Pharmacol. Rep. 63, 1310-1315. doi: 10.1016/S1734-1140(11)70695-8

Miyake, A., Friedman, N. P., Emerson, M. J., Witzki, A. H., Howerter, A., and Wager, T. D. (2000). The unity and diversity of executive functions and their contributions to complex "Frontal Lobe" tasks: a latent variable analysis. Cogn. Psychol. 41, 49-100. doi: 10.1006/cogp.1999.0734

Muller, U. J., Sturm, V., Voges, J., Heinze, H. J., Galazky, I., Heldmann, M., et al. (2009). Successful treatment of chronic resistant alcoholism by deep brain stimulation of nucleus accumbens: first experience with three cases. Pharmacopsychiatry 42, 288-291. doi: 10.1055/s-0029-1233489

Nakazato, M., Hashimoto, K., Schmidt, U., Tchanturia, K., Campbell, I. C., Collier, D. A., et al. (2010). Serum glutamine, set-shifting ability and anorexia nervosa. Ann. Gen. Psychiatry 9:29. doi: 10.1186/1744-859X-9-29

Nicolle, M. M., and Baxter, M. G. (2003). Glutamate receptor binding in the frontal cortex and dorsal striatum of aged rats with impaired attentional set-shifting. Eur. J. Neurosci. 18, 3335-3342. doi: 10.1111/j.1460-9568.2003.03077.x

Nordin, C., and Sjödin, I. (2006). CSF monoamine patterns in pathological gamblers and healthy controls. J. Psychiatr. Res. 40, 454-459. doi: 10.1016/j.jpsychires.2005.06.003

O'Brien, K. M., and Vincent, N. K. (2003). Psychiatric comorbidity in anorexia and bulimia nervosa: nature, prevalence, and causal relationships. Clin. Psychol. Rev. 23, 57-74. doi: 10.1016/S0272-7358(02)00201-5

Olive, M. F., Cleva, R. M., Kalivas, P. W., and Malcolm, R. J. (2012). Glutamatergic medications for the treatment of drug and behavioral addictions. Pharmacol. Biochem. Behav. 100, 801-810. doi: 10.1016/j.pbb.2011.04.015

Park, R. J., Dunn, B. D., and Barnard, P. J. (2011). Schematic models and modes of mind in anorexia nervosa I: a novel process account. Int. J. Cogn. Therapy 4, 415-437. doi: 10.1521/ijct.2011.4.4.415

Park, R. J., Dunn, B. D., and Barnard, P. J. (2012). Schematic models and modes of mind in anorexia nervosa II: implications for treatment and course. Int. J. Cogn. Therapy 5, 86-98. doi: 10.1521/ijct.2012.5.1.86

Pentkowski, N. S., Duke, F. D., Weber, S. M., Pockros, L. A., Teer, A. P., Hamilton, E. C., et al. (2010). Stimulation of medial prefrontal cortex serotonin 2C (5-HT 2C) receptors attenuates cocaine-seeking behavior. Neuropsychopharmacology 35, 2037-2048. doi: 10.1038/npp.2010.72

Perani, D., Garibotto, V., Gorini, A., Moresco, R. M., Henin, M., Panzacchi, A., et al. (2008). In vivo PET study of 5HT2A serotonin and D2 dopamine dysfunction in drug-naive obsessive-compulsive disorder. Neuroimage 42, 306-314. doi: 10.1016/j.neuroimage.2008.04.233

Pinto, A., Steinglass, J. E., Greene, A. L., Weber, E. U., and Simpson, H. B. (2014). Capacity to delay reward differentiates obsessive-compulsive disorder and obsessive-compulsive personality disorder. Biol. Psychiatry 75, 653-659. doi: 10.1016/j.biopsych.2013.09.007

Pitman, R. K. (1989). Animal models of compulsive behavior. Biol. Psychiatry 26, 189-198. doi: 10.1016/0006-3223(89)90022-X

Pittenger, C., Bloch, M. H., and Williams, K. (2011). Glutamate abnormalities in obsessive compulsive disorder: neurobiology, pathophysiology, and treatment. Pharmacol. Ther. 132, 314-332. doi: 10.1016/j.pharmthera.2011. 09.006 
Plaçais, P.-Y., and Preat, T. (2013). To favor survival under food shortage, the brain disables costly memory. Science 339, 440-442. doi: 10.1126/science. 1226018

Rauch, S. L. (2003). Neuroimaging and neurocircuitry models pertaining to the neurosurgical treatment of psychiatric disorders. Neurosurg. Clin. N. Am. 14, 213-223, vii-viii. doi: 10.1016/S1042-3680(02)00114-6

Remijnse, P. L., Nielen, M. M., Van Balkom, A. J., Cath, D. C., van Oppen, P., Uylings, H. B., et al. (2006). Reduced orbitofrontal-striatal activity on a reversal learning task in obsessive-compulsive disorder. Arch. Gen. Psychiatry 63, 1225-1236. doi: 10.1001/archpsyc.63.11.1225

Robbins, T. W. (2007). Shifting and stopping: fronto-striatal substrates, neurochemical modulation and clinical implications. Philos. Trans. R. Soc. B Biol. Sci. 362, 917-932. doi: 10.1098/rstb.2007.2097

Robbins, T. W., Gillan, C. M., Smith, D. G., De Wit, S., and Ersche, K. D. (2012). Neurocognitive endophenotypes of impulsivity and compulsivity: towards dimensional psychiatry. Trends Cogn. Sci. 16, 81-91. doi 10.1016/j.tics.2011.11.009

Roberts, M. E., Tchanturia, K., and Treasure, J. L. (2010). Exploring the neurocognitive signature of poor set-shifting in anorexia and bulimia nervosa. J. Psychiatr Res. 44, 964-970. doi: 10.1016/j.jpsychires.2010.03.001

Rothemund, Y., Buchwald, C., Georgiewa, P., Bohner, G., Bauknecht, H. C., Ballmaier, M., et al. (2011). Compulsivity predicts fronto striatal activation in severely anorectic individuals. Neuroscience 197, 242-250. doi: 10.1016/j.neuroscience.2011.09.016

Routtenberg, A., and Kuznesof, A. W. (1967). Self-starvation of rats living in activity wheels on a restricted feeding schedule. J. Comp. Physiol. Psychol. 64, 414-421. doi: $10.1037 / \mathrm{h} 0025205$

Salkovskis, P. M. (1999). Understanding and treating obsessive-compulsive disorder Behav. Res. Ther. 37(Suppl. 1), S29-S52. doi: 10.1016/S0005-7967(99)00049-2

Saraswat, N., Ranjan, S., and Ram, D. (2006). Set-shifting and selective attentional impairment in alcoholism and its relation with drinking variables. Indian J. Psychiatry 48:47. doi: 10.4103/0019-5545.31619

Sarrar, L., Ehrlich, S., Merle, J. V., Pfeiffer, E., Lehmkuhl, U., and Schneider, N. (2011). Cognitive flexibility and Agouti-related protein in adolescent patients with anorexia nervosa. Psychoneuroendocrinology 36, 1396-1406. doi 10.1016/j.psyneuen.2011.03.014

Saxena, S., Brody, A. L., Schwartz, J. M., and Baxter, L. R. (1998). Neuroimaging and frontal-subcortical circuitry in obsessive-compulsive disorder. Br. J. Psychiatry Suppl. 26-37.

Scarone, S., Colombo, C., Livian, S., Abbruzzese, M., Ronchi, P., Locatelli, M., et al (1992). Increased right caudate nucleus size in obsessive-compulsive disorder: detection with magnetic resonance imaging. Psychiatry Res. 45, 115-121. doi: 10.1016/0925-4927(92)90005-O

Scheurink, A. J., Boersma, G. J., Nergardh, R., and Sodersten, P. (2010). Neurobiology of hyperactivity and reward: agreeable restlessness in anorexia nervosa Physiol. Behav. 100, 490-495. doi: 10.1016/j.physbeh.2010.03.016

Schwabe, L., Oitzl, M. S., Philippsen, C., Richter, S., Bohringer, A., Wippich, W., et al. (2007). Stress modulates the use of spatial versus stimulus-response learning strategies in humans. Learn. Mem. 14, 109-116. doi: 10.1101/lm.435807

Schwabe, L., and Wolf, O. T. (2009). Stress prompts habit behavior in humans. J. Neurosci. 29, 7191-7198. doi: 10.1523/jneurosci.0979-09.2009

Selby, E. A., Wonderlich, S. A., Crosby, R. D., Engel, S. G., Panza, E., Mitchell, J. E., et al. (2014). Nothing tastes as good as thin feels: low positive emotion differentiation and weight-loss activities in anorexia nervosa. Clin. Psychol. Sci. 2, 514-531. doi: 10.1177/2167702613512794

Simansky, K. J. (1996). Serotonergic control of the organization of feeding and satiety. Behav. Brain Res. 73, 37-42. doi: 10.1016/0166-4328(96) 00066-6

Steinglass, J., Albano, A. M., Simpson, H. B., Carpenter, K., Schebendach, J., and Attia, E. (2012a). Fear of food as a treatment target: exposure and response prevention for anorexia nervosa in an open series. Int. J. Eat. Disord. 45, 615-621. doi: 10.1002/eat.20936

Steinglass, J., Figner, B., Berkowitz, S., Simpson, H. B., Weber, E. U., and Walsh, B. T. (2012b). Increased capacity to delay reward in anorexia nervosa. J. Int Neuropsychol. Soc. 18, 773-780. doi: 10.1017/S1355617712000446

Steinglass, J., and Walsh, B. T. (2006). Habit learning and anorexia nervosa: a cognitive neuroscience hypothesis. Int. J. Eat. Disord. 39, 267-275. doi: 10.1002/eat.20244
Steinglass, J. E., Walsh, B. T., and Stern, Y. (2006). Set shifting deficit in anorexia nervosa. J. Int. Neuropsychol. Soc. 12, 431-435. doi: 10.1017/S1355617706060528

Tchanturia, K., Anderluh, M. B., Morris, R. G., Rabe-Hesketh, S., Collier, D. A., Sanchez, P., et al. (2004). Cognitive flexibility in anorexia nervosa and bulimia nervosa. J. Int. Neuropsychol. Soc. 10, 513-520. doi: 10.1017/S1355617704104086

Tchanturia, K., Davies, H., and Campbell, I. C. (2007a). Cognitive remediation therapy for patients with anorexia nervosa: preliminary findings. Ann. Gen. Psychiatry 6:14. doi: 10.1186/1744-859X-6-14

Tchanturia, K., Liao, P. C., Uher, R., Lawrence, N., Treasure, J., and Campbell, I. C. (2007b). An investigation of decision making in anorexia nervosa using the Iowa Gambling Task and skin conductance measurements. J. Int. Neuropsychol. Soc. 13, 635-641. doi: 10.1017/s1355617707070798

Tizabi, Y., Louis, V. A., Taylor, C. T., Waxman, D., Culver, K. E., and Szechtman, H. (2002). Effect of nicotine on quinpirole-induced checking behavior in rats: implications for obsessive-compulsive disorder. Biol. Psychiatry 51, 164-171. doi: 10.1016/S0006-3223(01)01207-0

Tricomi, E., Balleine, B. W., and O’Doherty, J. P. (2009). A specific role for posterior dorsolateral striatum in human habit learning. Eur. J. Neurosci. 29, 2225-2232. doi: 10.1111/j.1460-9568.2009.06796.x

Tsaltas, E., Kontis, D., Chrysikakou, S., Giannou, H., Biba, A., Pallidi, S., et al. (2005). Reinforced spatial alternation as an animal model of obsessivecompulsive disorder (OCD): investigation of 5-HT2C and 5-HT1D receptor involvement in OCD pathophysiology. Biol. Psychiatry 57, 1176-1185. doi: 10.1016/j.biopsych.2005.02.020

Uher, R., Murphy, T., Brammer, M. J., Dalgleish, T., Phillips, M. L., Ng, V. W., et al. (2004). Medial prefrontal cortex activity associated with symptom provocation in eating disorders. Am. J. Psychiatry 161, 1238-1246. doi: 10.1176/appi.ajp.161.7.1238

Valerius, G., Lumpp, A., Kuelz, A. K., Freyer, T., and Voderholzer, U. (2008). Reversal learning as a neuropsychological indicator for the neuropathology of obsessive compulsive disorder? A behavioral study. J. Neuropsychiatry Clin. Neurosci. 20, 210-218. doi: 10.1176/appi.neuropsych.20.2.210

Van den Eynde, F., Guillaume, S., Broadbent, H., Campbell, I. C., and Schmidt, U. (2013). Repetitive transcranial magnetic stimulation in anorexia nervosa: a pilot study. Eur. Psychiatry 28, 98-101. doi: 10.1016/j.eurpsy.2011.06.002

van Hell, H. H., Vink, M., Ossewaarde, L., Jager, G., Kahn, R. S., and Ramsey, N. F. (2010). Chronic effects of cannabis use on the human reward system: an fMRI study. Eur. Neuropsychopharmacol. 20, 153-163. doi: 10.1016/j.euroneuro.2009.11.010

Verdejo-Garcia, A., Benbrook, A., Funderburk, F., David, P., Cadet, J. L., and Bolla, K. I. (2007). The differential relationship between cocaine use and marijuana use on decision-making performance over repeat testing with the Iowa Gambling Task. Drug Alcohol Depend. 90, 2-11. doi: 10.1016/j.drugalcdep.2007.02.004

Verhagen, L. A., Luijendijk, M. C., Hillebrand, J. J., and Adan, R. A. (2009a). Dopamine antagonism inhibits anorectic behavior in an animal model for anorexia nervosa. Eur. Neuropsychopharmacol. 19, 153-160. doi: 10.1016/j.euroneuro.2008.09.005

Verhagen, L. A., Luijendijk, M. C., Korte-Bouws, G. A., Korte, S. M., and Adan, R. A. (2009b). Dopamine and serotonin release in the nucleus accumbens during starvation-induced hyperactivity. Eur. Neuropsychopharmacol. 19, 309-316. doi: 10.1016/j.euroneuro.2008.12.008

Volkow, N. D., Fowler, J. S., and Wang, G. J. (2002). Role of dopamine in drug reinforcement and addiction in humans: results from imaging studies. Behav. Pharmacol. 13, 355-366. doi: 10.1097/00008877-200209000-00008

Volkow, N. D., Fowler, J. S., Wang, G. J., Baler, R., and Telang, F. (2009). Imaging dopamine's role in drug abuse and addiction. Neuropharmacology 1, 3-8. doi: 10.1016/j.neuropharm.2008.05.022

Volkow, N. D., Fowler, J. S., Wang, G. J., Swanson, J. M., and Telang, F. (2007a). Dopamine in drug abuse and addiction: results of imaging studies and treatment implications. Arch. Neurol. 64, 1575-1579. doi: 10.1001/archneur.64.11.1575

Volkow, N. D., Wang, G.-J., Telang, F., Fowler, J. S., Logan, J., Jayne, M., et al. (2007b). Profound decreases in dopamine release in striatum in detoxified alcoholics: possible orbitofrontal involvement. J. Neurosci. 27, 12700-12706. doi: 10.1523/JNEUROSCI.3371-07.2007

Volkow, N., Wang, G., Fowler, J., Gatley, S., Ding, Y., Logan, J., et al. (1996). Relationship between psychostimulant-induced "high" and dopamine transporter occupancy. Proc. Natl. Acad. Sci. U.S.A. 93, 10388-10392. doi: 10.1073/pnas.93.19.10388 
Volkow, N. D., Wang, G. J., Fowler, J. S., and Tomasi, D. (2012a). Addiction circuitry in the human brain. Annu. Rev. Pharmacol. Toxicol. 52, 321-336. doi: 10.1146/annurev-pharmtox-010611-134625

Volkow, N. D., Wang, G. J., Fowler, J. S., Tomasi, D., and Baler, R. (2012b). Food and drug reward: overlapping circuits in human obesity and addiction. Curr. Top. Behav. Neurosci. 11, 1-24. doi: 10.1007/7854_2011_169

Volkow, N. D., Wang, G.-J., Ma, Y., Fowler, J. S., Zhu, W., Maynard, L., et al. (2003) Expectation enhances the regional brain metabolic and the reinforcing effects of stimulants in cocaine abusers. J. Neurosci. 23, 11461-11468.

Volkow, N. D., Wang, G.-J., Telang, F., Fowler, J. S., Logan, J., Childress, A.-R., et al. (2006). Cocaine cues and dopamine in dorsal striatum: mechanism of craving in cocaine addiction. J. Neurosci. 26, 6583-6588. doi: 10.1523/JNEUROSCI.154406.2006

Voon, V., Fernagut, P. O., Wickens, J., Baunez, C., Rodriguez, M., Pavon, N. et al. (2009). Chronic dopaminergic stimulation in Parkinson's disease: from dyskinesias to impulse control disorders. Lancet Neurol. 8, 1140-1149. doi: 10.1016/S1474-4422(09)70287-X

Wagner, A., Aizenstein, H., Venkatraman, V., Fudge, J., May, J., Mazurkewicz, L., et al. (2007). Altered reward processing in women recovered from anorexia nervosa. Am. J. Psychiatry 164, 1842-1849. doi: 10.1176/appi.ajp.2007. 07040575

Walsh, B. T. (2013). The enigmatic persistence of anorexia nervosa. Am. J. Psychiatry 170, 477-484. doi: 10.1176/appi.ajp.2012.12081074

Wikler, A. (1973). Dynamics of drug dependence. Implications of a conditioning theory for research and treatment. Arch. Gen. Psychiatry 28, 611-616. doi 10.1001/archpsyc.1973.01750350005001
Wise, R. A. (2002). Brain reward circuitry: insights from unsensed incentives. Neuron 36, 229-240. doi: 10.1016/S0896-6273(02)00965-0

Wolf, M. E. (2002). Addiction: making the connection between behavioral changes and neuronal plasticity in specific pathways. Mol. Interv. 2, 146-157. doi: 10.1124/mi.2.3.146

Wu, H., Van Dyck-Lippens, P. J., Santegoeds, R., Van Kuyck, K., Gabriã, L., Lin, G., et al. (2012). Deep-brain stimulation for anorexia nervosa. World Neurosurg. 80, S29.e1-S29.e10. doi: 10.1016/j.wneu.2012.06.039

Zink, C. F., and Weinberger, D. R. (2010). Cracking the moody brain: the rewards of self starvation. Nat. Med. 16, 1382-1383. doi: 10.1038/nm1210-1382

Conflict of Interest Statement: The authors declare that the research was conducted in the absence of any commercial or financial relationships that could be construed as a potential conflict of interest.

Received: 29 April 2014; accepted: 01 July 2014; published online: 17 July 2014. Citation: Godier LR and Park RJ (2014) Compulsivity in anorexia nervosa: a transdiagnostic concept. Front. Psychol. 5:778. doi: 10.3389/fpsyg.2014.00778

This article was submitted to Eating Behavior, a section of the journal Frontiers in Psychology.

Copyright (C) 2014 Godier and Park. This is an open-access article distributed under the terms of the Creative Commons Attribution License (CC BY). The use, distribution or reproduction in other forums is permitted, provided the original author (s) or licensor are credited and that the original publication in this journal is cited, in accordance with accepted academic practice. No use, distribution or reproduction is permitted which does not comply with these terms. 